\title{
Hygroscopic behavior of multicomponent organic aerosols and their internal mixtures with ammonium sulfate
}

\author{
Bo Jing ${ }^{1,2, *}$, Shengrui Tong ${ }^{1, *}$, Qifan Liu ${ }^{1}, \mathrm{Kun} \mathrm{Li}^{1}$, Weigang Wang ${ }^{1}$, Yunhong Zhang ${ }^{2}$, and Maofa Ge ${ }^{1}$ \\ ${ }^{1}$ Beijing National Laboratory for Molecular Sciences (BNLMS), State Key Laboratory for Structural Chemistry of Unstable \\ and Stable Species, Institute of Chemistry, Chinese Academy of Sciences, Beijing 100190, China \\ ${ }^{2}$ The Institute of Chemical Physics, School of Chemistry, Beijing Institute of Technology, Beijing 100081, China \\ *These authors contributed equally to this work.
}

Correspondence to: Maofa Ge (gemaofa@iccas.ac.cn) and Yunhong Zhang (yhz@bit.edu.cn)

Received: 14 July 2015 - Published in Atmos. Chem. Phys. Discuss.: 28 August 2015

Revised: 9 March 2016 - Accepted: 17 March 2016 - Published: 30 March 2016

\begin{abstract}
Water-soluble organic compounds (WSOCs) are important components of organics in the atmospheric fine particulate matter. Although WSOCs play an important role in the hygroscopicity of aerosols, knowledge on the water uptake behavior of internally mixed WSOC aerosols remains limited. Here, the hygroscopic properties of single components such as levoglucosan, oxalic acid, malonic acid, succinic acid, phthalic acid, and multicomponent WSOC aerosols mainly involving oxalic acid are investigated with the hygroscopicity tandem differential mobility analyzer (HTDMA). The coexisting hygroscopic species including levoglucosan, malonic acid, and phthalic acid have a strong influence on the hygroscopic growth and phase behavior of oxalic acid, even suppressing its crystallization completely during the drying process. The phase behaviors of oxalic acid / levoglucosan mixed particles are confirmed by infrared spectra. The discrepancies between measured growth factors and predictions from Extended Aerosol Inorganics Model (E-AIM) with the Universal Quasi-Chemical Functional Group Activity Coefficient (UNIFAC) method and Zdanovskii-Stokes-Robinson (ZSR) approach increase at medium and high relative humidity (RH) assuming oxalic acid in a crystalline solid state. For the internal mixture of oxalic acid with levoglucosan or succinic acid, there is enhanced water uptake at high RH compared to the model predictions based on reasonable oxalic acid phase assumption. Organic mixture has more complex effects on the hygroscopicity of ammonium sulfate than single species. Although hygroscopic species such as levoglucosan account for a small fraction in the multicomponent aerosols, they
\end{abstract}

may still strongly influence the hygroscopic behavior of ammonium sulfate by changing the phase state of oxalic acid which plays the role of "intermediate" species. Considering the abundance of oxalic acid in the atmospheric aerosols, its mixtures with hygroscopic species may significantly promote water uptake under high RH conditions and thus affect the cloud condensation nuclei $(\mathrm{CCN})$ activity, optical properties, and chemical reactivity of atmospheric particles.

\section{Introduction}

Atmospheric aerosols can strongly affect the Earth's climate and atmospheric processes (Ramanathan et al., 2001). As one of the most important physicochemical properties, the hygroscopic properties determine the size, concentration, and phase state of aerosol particles and thus contribute to radiative forcing on the climate system, including both the direct forcing by absorbing or scattering light and indirect forcing through activation of cloud condensation nuclei (CCN) (Haywood and Boucher, 2000; Kanakidou et al., 2005). In addition, the water uptake of atmospheric aerosols influences their atmospheric lifetimes, reactivity, air quality, and even human health (Pandis et al., 1995; Krueger et al., 2003; Chan and Yao, 2008; Pöschl, 2005; Schneidemesser et al., 2015).

For the atmospheric fine particulate matter, the organic components can usually occupy $20-90 \%$ by mass (Kanakidou et al., 2005; Zhang et al., 2007), a large fraction of which is composed of water-soluble organic compounds (WSOCs) (Saxena and Hildemann, 1996; Graham et al., 2002; Decesari 
Table 1. Chemical properties of investigated organic species.

\begin{tabular}{llrrl}
\hline Substance & Chemical formula & $\mathrm{MW}\left(\mathrm{g} \mathrm{mol}^{-1}\right)$ & $\rho\left(\mathrm{g} \mathrm{cm}^{-3}\right)$ & Supplier/purity \\
\hline Ammonium sulfate & $\left(\mathrm{NH}_{4}\right)_{2} \mathrm{SO}_{4}$ & 132.1 & 1.77 & Alfa Aesar, 99.95\% \\
Levoglucosan & $\mathrm{C}_{6} \mathrm{H}_{10} \mathrm{O}_{5}$ & 162.1 & 1.62 & Aldrich, 99\% \\
Oxalic acid & $\mathrm{C}_{2} \mathrm{H}_{2} \mathrm{O}_{4}$ & 90 & 1.9 & Aldrich, 99.999\% \\
Oxalic acid & $\mathrm{C}_{2} \mathrm{H}_{2} \mathrm{O}_{4}$ & 126 & 1.65 & - \\
(dihydrate) & $2 \mathrm{H}_{2} \mathrm{O}$ & & & \\
Malonic acid & $\mathrm{C}_{3} \mathrm{H}_{4} \mathrm{O}_{4}$ & 104.1 & 1.62 & Sigma-Aldrich, 99\% \\
Succinic acid & $\mathrm{C}_{4} \mathrm{H}_{6} \mathrm{O}_{4}$ & 118.1 & 1.57 & Sigma-Aldrich, $\geq 99.5 \%$ \\
Phthalic acid & $\mathrm{C}_{8} \mathrm{H}_{6} \mathrm{O}_{4}$ & 166.1 & 1.59 & Sigma-Aldrich, $\geq 99.5 \%$ \\
\hline
\end{tabular}

et al., 2005). Hygroscopic properties of aerosols are mainly affected by their chemical composition. Therefore, watersoluble organic compounds can significantly alter aerosols' hygroscopicity (Saxena et al., 1995; Mircea et al., 2005). Compared with the thorough study on hygroscopic properties of atmospheric inorganic components, the knowledge on the hygroscopic behavior of WSOCs still remains relatively limited (Kanakidou et al., 2005; Jimenez et al., 2009; Hallquist et al., 2009). Due to complexity of organic matter, it is difficult to conduct a comprehensive investigation on the hygroscopic behavior of all the organic compounds. To solve this problem, a set of identified model organic compounds have been proposed to represent the WSOCs (Fuzzi et al., 2001; Mayol-Bracero, 2002; Decesari et al., 2006). According to the approach suggested by Fuzzi et al. (2001), the WSOCs can be generally separated into three categories based on acid or base character: (i) neutral compounds, (ii) mono-/dicarboxylic acids, and (iii) polycarboxylic acids such as humic-like organic polymers. Levoglucosan, as a tracer of biomass burning products (Simoneit et al., 1999), is often selected to represent the neutral compounds (Decesari et al., 2006; Svenningsson et al., 2006). Dicarboxylic acids are ubiquitous in the atmosphere and have been identified as significant components of the organic matter in urban and remote atmospheric aerosols (Chebbi and Carlier, 1996; Mochida et al., 2003; Kundu et al., 2010). Field measurements have shown that oxalic acid is usually the dominant dicarboxylic acid in aerosol particles, followed by malonic acid, succinic acid, and phthalic acid (Hegde and Kawamura, 2012; Kawamura et al., 2013).

The hygroscopic properties of levoglucosan and the low molecular weight dicarboxylic acids have been investigated widely with different measurement methods in the past several years (Peng et al., 2001; Prenni et al., 2001; Brooks et al., 2002; Braban et al., 2003; Mochida and Kawamura, 2004; Parsons et al., 2004b; Chan et al., 2005; Yeung and Chan, 2010; Zamora et al., 2011; Ma et al., 2013; Minambres et al., 2013; Ghorai et al., 2014). Most studies have focused on the hygroscopicity of aerosol particles containing only a single organic component or its mixture with an inorganic salt (Lightstone et al., 2000; Cruz and Pandis, 2000;
Hameri et al., 2002; Prenni et al., 2003; Wise et al., 2003; Braban and Abbatt, 2004; Parsons et al., 2004a; Ling and Chan, 2008; Zardini et al., 2008; Pope et al., 2010; Peckhaus et al., 2012; Ghorai et al., 2014). It has been found that water uptake and phase behavior of the organic aerosols is complex. The hygroscopicity of WSOCs is dependent on their composition, mixing state, and phase state. Even for the same single-component WSOC, differences still existed in measurements of hygroscopic growth with various measurement technologies (Zamora et al., 2011). Previous HTDMA measurements showed that oxalic acid particles had obvious water uptake upon hydration below $90 \%$ relative humidity $(\mathrm{RH})$ while it was not observed in the electrodynamic balance (EDB) measurements (Prenni et al., 2001; Peng et al., 2001). This discrepancy could be attributed to initial physical state of aerosol particles, which has considerable influence on water uptake behaviors of atmospheric aerosols (Martin, 2000; Mikhailov et al., 2009). Due to complex interactions among organic mixtures, organic aerosol fractions are more likely to form liquid or amorphous rather than crystalline phases (Mikhailov et al., 2009; Marcolli et al., 2004; Cappa et al., 2008). Considering the potential impact of the interactions between organic species on their hygroscopicity, further study is needed on the hygroscopic behaviors of multicomponent organic aerosols and their mixtures with ammonium sulfate (Marcolli et al., 2004; Moore and Raymond, 2008). Additionally, measurements for the hygroscopic growth of internally mixed organic aerosols can be used to assess the prediction reliability of relevant thermodynamic models (Peng et al., 2001).

In this study, the hygroscopic behaviors of multicomponent organic aerosol particles were investigated with a hygroscopicity tandem differential mobility analyzers (HTDMA) system. Levoglucosan, oxalic acid, malonic acid, succinic acid, and phthalic acid were chosen as the surrogates of WSOC. The attenuated total reflectance Fourier transform infrared (ATR-FTIR) spectroscopy was used to reveal information about molecular interactions and phase transitions in the aerosol particles. Several model methods were applied to predict the water uptake of these organic aerosols including Extended Aerosol Inorganics Model (E-AIM, available at http: 
Table 2. Chemical composition and $\mathrm{O} / \mathrm{C}$ ratio of mixtures used in experiments.

\begin{tabular}{lcc}
\hline Mixture & Mass ratio & O / C ratio \\
\hline Levoglucosan (Lev) + oxalic acid (OA) & $1: 1$ & 1.27 \\
Levoglucosan (Lev) + oxalic acid (OA) & $1: 3$ & 1.58 \\
Levoglucosan (Lev) + oxalic acid (OA) & $3: 1$ & 1.03 \\
Levoglucosan (Lev) + phthalic acid (PA) & $1: 1$ & 0.64 \\
Oxalic acid (OA) + malonic acid (MA) & $1: 1$ & 1.62 \\
Oxalic acid (OA) + succinic acid (SA) & $1: 1$ & 1.40 \\
Oxalic acid (OA) + phthalic acid (PA) & $1: 1$ & 0.97 \\
Levoglucosan (Lev) + oxalic acid (OA) + phthalic acid (PA) & $1: 1: 1$ & 0.93 \\
\hline
\end{tabular}

//www.aim.env.uea.ac.uk/aim/aim.php) in combination with the UNIFAC (Universal Quasi-Chemical Functional Group Activity Coefficient) method, Zdanovskii-Stokes-Robinson (ZSR) method, and ideal solution model. Additionally, the nonideality and CCN activity of WSOC aerosols were evaluated. Finally, the influence of organic mixture on the water uptake behavior of ammonium sulfate was determined.

\section{Experiment and method}

\subsection{Hygroscopic growth measurements}

The hygroscopicity tandem differential mobility analyzer (HTDMA) used here has been described in previous studies (Lei et al., 2014; Liu et al., 2016). The schematic of HTDMA system is shown in Fig. 1, mainly including three parts: (1) the aerosol particles' generation and drying section; (2) the particles' size selection and humidity control apparatus; and (3) the detection system for number size distributions of the humidified aerosols. The wet aerosol particles were produced from a constant output atomizer (MSP 1500) containing aqueous solutions of the organic compounds. Chemical properties and mixture composition of the substances investigated were listed in Tables 1 and 2. Each pure component or mixture was completely dissolved in ultrapure water (EASY Pure ${ }^{\circledR}$ II UF ultrapure water system, $18.2 \mathrm{M} \Omega \mathrm{cm}$ ) to form a dilute solution with concentration of around $0.1 \mathrm{wt} \%$. The nebulized aerosols were subsequently dried to $\mathrm{RH}<5 \%$ in silica gel diffusion dryers coupled with a Nafion gas dryer (Perma Pure Inc., USA).

The initial polydisperse aerosol particles were then charged and passed through the first differential mobility analyzer (DMA1), where nearly monodisperse aerosol particles with the desired particle diameter of $100 \mathrm{~nm}$ were selected. The size-selected particles then entered into a humidification system consisting of two Nafion conditioner tubes. The aerosols were prehumidified in the first Nafion conditioner tube and accomplished humidification in the second Nafion tube at a desired relative humidity. The residence time of aerosol particles at a given RH before entering into DMA2 was about $5 \mathrm{~s}$ in the humidification section. The size distribu-

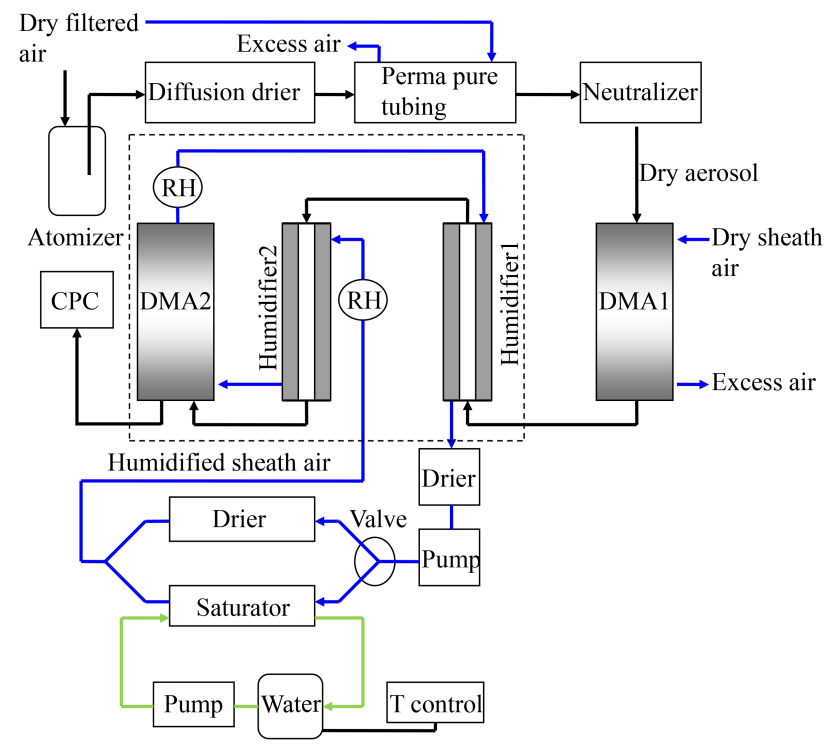

Figure 1. Schematic setup of the hygroscopicity tandem differential mobility analyzer (HTDMA) system.

tion of humidified aerosol particles was measured by the second differential mobility analyzer (DMA2) and a condensation particle counter (CPC, MSP 1500). The inversion of HTDMA measurement data was based on a log-normal size distribution approximation (Stolzenburg and McMurry, 2008). The ratio of sheath air to aerosol flow rate was maintained at $10: 1$ for both DMAs. In our system, sheath air flows were recirculated in a closed-loop arrangement to ensure relative humidity in the humidification section and DMA2 was equal. A dew-point hygrometer (Michell, UK) was used to monitor the relative humidity of sheath flow in the DMA2, with an uncertainty of $\pm 0.08 \% \mathrm{RH}$. All experiments were performed at ambient temperature $(297 \pm 1 \mathrm{~K})$. In our measurements for organic mixtures, no obvious reduction of particle diameter was observed during measurements in DMA2 at $\mathrm{RH}<5 \%$, indicating the evaporation of organics was suppressed in the mixtures.

Hygroscopic growth factor (GF), indicating water uptake ability of aerosol particles, is defined as the ratio of particle 
mobility diameter at a specific RH to the mobility diameter measured in DMA2 at $\mathrm{RH}<5 \%$. All results are the average of at least three measurements and uncertainty in our measured growth factors is within 0.02 . The results of instrument performance evaluation can be seen in Fig. S1 in the Supplement.

\subsection{Infrared absorption measurements}

The attenuated total reflectance Fourier transform infrared (ATR-FTIR) spectroscopy is a valuable tool to probe the hygroscopic process of aerosol particles. The ATR horizontal cell apparatus (Pike Technologies) was similar to our previous studies (Zhang et al., 2014) and a Ge crystal instead of ZnSe was used as the substrate due to acidity of oxalic acid. Aerosol particles produced from aqueous samples ( $2.0 \mathrm{wt} \%$ ) in a constant output atomizer passed through the silica gel diffusion dryer and then deposited on the Ge crystal substrate, resulting in a homogeneously dispersed sample. To obtain enough signal-to-noise level spectrum, the aerosol particles used for infrared measurements did not experience size selection. The upper limit of particle size was below $2 \mu \mathrm{m}$. The RH inside the ATR cell was controlled by a nitrogen flow which was mixed by dry nitrogen with nitrogen saturated with water vapor. A humidity probe accurate to $\pm 2 \%$ (HMP 237, Vaisala) was placed at the exit of the cell to monitor the RH. To ensure hygroscopic equilibration, each RH was maintained 30 min before making measurement. Infrared spectra at various RHs during humidification were measured in the spectral range from 4000 to $750 \mathrm{~cm}^{-1}$ with $4 \mathrm{~cm}^{-1}$ resolution by averaging 64 scans using a Thermo Nicolet 6700 FTIR spectrometer equipped with a high-sensitivity mercury cadmium telluride (MCT) detector. All spectra reported here were referenced to the background signal of the blank Ge crystal under dry conditions and gas water lines have been subtracted.

\section{Modeling methods}

\subsection{Hygroscopic growth treatment}

To minimize the Kelvin curvature effect for submicron particles measured in the HTDMA, the relative humidity $(\mathrm{RH})$ was converted to water activity $\left(a_{\mathrm{w}}\right)$ by Köhler equation:

$\mathrm{RH}=a_{\mathrm{w}} \exp \left(\frac{4 \sigma_{\mathrm{sol}} M_{\mathrm{w}}}{R T \rho_{\mathrm{w}} D_{p}}\right)$.

Here, $\sigma_{\mathrm{sol}}$ is the surface tension of droplet, $M_{\mathrm{w}}$ is the molar mass of water, $R$ is the ideal gas constant, $T$ is the temperature, $\rho_{\mathrm{W}}$ is the density of water, and $D_{p}$ is the droplet diameter. The surface tension of droplet is set to be that of pure water $\left(0.072 \mathrm{~J} \mathrm{~m}^{-2}\right)$. Although organics in the droplet may reduce its surface tension, $a_{\mathrm{w}}$ error caused by approximation was negligible compared with the uncertainty of the RH measurement.
Table 3. The three-parameter fit values for the hygroscopic growth of the investigated organic aerosol particles with Eq. (2).

\begin{tabular}{lrrrr}
\hline Substance & $a$ & $b$ & $c$ & $R^{2}$ \\
\hline Levoglucosan & 0.4315 & -0.4929 & 0.2789 & 0.9997 \\
Malonic acid & 0.2512 & 0.2493 & -0.1236 & 0.9959 \\
Phthalic acid & 0.4368 & -0.6003 & 0.2737 & 0.9910 \\
\hline
\end{tabular}

According to the expression proposed by Kreidenweis et al. (2005), continuous water uptake behavior of individual species can be well described with a polynomial fit equation:

$\mathrm{GF}=\left[1+\left(a+b \cdot a_{\mathrm{w}}+c \cdot a_{\mathrm{w}}^{2}\right) \frac{a_{\mathrm{w}}}{1-a_{\mathrm{w}}}\right]^{1 / 3}$.

The coefficients $a, b$, and $c$ obtained by Eq. (2) fitting to GF$a_{\mathrm{w}}$ measurement data are given in Table 3 .

\subsection{Hygroscopic growth prediction}

The ZSR method is widely used to estimate hygroscopic growth of internally mixed particles by assuming independent water uptake of the pure components in the particles at a given RH (Prenni et al., 2003; Brooks et al., 2004; Zamora and Jacobson, 2013). This method has been successfully applied to predict water uptake of various mixed systems containing inorganic salts and organic species in the atmosphere. The hygroscopic growth factor $\left(\mathrm{GF}_{\operatorname{mix}}\right)$ of the mixed particles can be calculated by ZSR relation (Stokes and Robinson, 1966; Malm and Kreidenweis, 1997), as following:

$\mathrm{GF}_{\operatorname{mix}}=\left(\sum_{k} \varepsilon_{k} \mathrm{GF}_{k}^{3}\right)^{1 / 3}$

where $\mathrm{GF}_{k}$ is the hygroscopic growth factor of pure component $k$ and $\varepsilon_{k}$ is the respective volume fraction in the dry mixture. This equation is derived by assumption that water content of mixture is equal to the sum of water uptake of pure components. The volume fraction $\left(\varepsilon_{i}\right)$ of component $i$ is calculated as:

$\varepsilon_{i}=\frac{\left(w_{i} / \rho_{i}\right)}{\sum_{k}\left(w_{k} / \rho_{k}\right)}$,

where $w_{i}$ is the mass fraction of species $i$ and $\rho_{i}$ is the respective density. Despite its simple assumption that each component in the mixture takes up water independently, the ZSR rule usually could well describe the hygroscopic growth of mixed particles with all components in the aqueous phase. For liquid particles, the large discrepancies between ZSR predictions and measurements can be attributed to the chemical interactions between components (Chan and Chan, 2003; Zardini et al., 2008). 
The E-AIM, developed by Wexler and Clegg (2002), can be used to treat the solution thermodynamics including prediction of the water activity, phase state, and equilibrium partitioning of the atmospheric inorganic aerosol systems. EAIM was later extended to include organic components by combining with the widely applied UNIFAC model (Fredenslund et al., 1975; Hansen et al., 1991; Wittig et al., 2003). The UNIFAC model, based on functional group contributions, can predict water activity coefficients for aqueous organic mixtures with various compositions. Due to hydrogen bonding interactions between polar groups, the standard UNIFAC model is not suitable for organic compounds with two highly polar functional groups separated by less than three or four carbon atoms, especially low molecular weight dicarboxylic acids (Peng et al., 2001). Peng et al. (2001) had revised UNIFAC parameters involving interactions between hydroxyl/carboxyl groups and water to accurately predict water activity for several individual dicarboxylic acids. Here the UNIFAC model with parameters modified by Peng et al. (2001) was used for WSOCs studied in this work. Considering that the measured GFs are calculated from the lowest $\mathrm{RH} \sim 4 \%$, the predicted GFs from E-AIM are also obtained from the same lowest RH. It should be noted that the residual water in the particles at the lowest $\mathrm{RH} \sim 4 \%$ are so slight that it could hardly result in significant difference between the predicted GFs from the lowest RH $(\sim 4 \%)$ or dry condition $(0 \% \mathrm{RH})$.

For the ideal solution, the water activity $a_{\mathrm{w}}$ is equal to the mole fraction of water in the solution (Raoult's law), seen in Eq. (5). Based on the ideal solution assumption, this model may fail to predict water activity of solutions containing electrolyte components or organic compounds with nonideal interaction. Previous investigations have demonstrated the ideal solution model was a useful tool to predict the hygroscopic growth of atmospheric organics such as humic-like substances, levoglucosan, and oxalic acid (Gysel et al., 2004; Mochida and Kawamura, 2004; Mikhailov et al., 2009). This is demonstrated by:

$a_{\mathrm{w}}=\frac{n_{\mathrm{w}}}{n_{\mathrm{w}}+n_{\mathrm{s}}}$,

where $n_{\mathrm{w}}$ and $n_{\mathrm{s}}$ are the mole numbers of water and solute, respectively.

Considering aerosol droplets may be deviated from ideal solution due to large solute concentrations and complex interactions between solutes, the van 't Hoff factor $i$ was used to evaluate non-ideality of solution (Low, 1969; Pruppacher and Klett, 1997). The van 't Hoff factor is equal to the numbers of dissociated ions per solute molecule, usually defined as following form:

$a_{\mathrm{w}}^{-1}=1+i \frac{n_{\mathrm{s}}}{n_{\mathrm{w}}}$,

where $n_{\mathrm{S}}$ is the sum of the mole number of all the solutes and $n_{\mathrm{w}}$ is the mole number of water in solution.

\subsection{Single hygroscopicity parameter $\kappa$}

According to $\kappa$-Köhler theory proposed by Petters and Kreidenweis (2007), a single hygroscopicity parameter $\kappa$ for describing the hygroscopic growth ability of aerosol particles, can be obtained based on hygroscopic growth measurements under subsaturated conditions (Carrico et al., 2008):

$\kappa=\frac{\left(\mathrm{GF}^{3}-1\right)\left(1-a_{\mathrm{w}}\right)}{a_{\mathrm{w}}}$,

where $a_{\mathrm{w}}$ is the water activity and GF is the respective hygroscopic growth factor. For organic compounds with continuous water uptake under subsaturated conditions, it was found that the $\kappa$ value based on the GF measurements from HTDMA around $90 \%$ RH can be used to assess the CCN activity of aerosols (Petters and Kreidenweis, 2007; Chan et al., 2008).

\section{Results and discussion}

\subsection{Hygroscopic growth of individual component aerosols}

Hygroscopic behaviors of dicarboxylic acids including oxalic acid (OA), malonic acid (MA), succinic acid (SA), and phthalic acid (PA) for $100 \mathrm{~nm}$ initial aerosol particles are presented in Fig. 2. For MA and PA with significant hygroscopic growth, predictions from E-AIM and ideal solution model are also shown. As can be seen from Fig. 2a, the GF of OA particles does not increase below $30 \% \mathrm{RH}$ and then keeps around 1.02 until $90 \% \mathrm{RH}$. The slight increase of GF suggests water absorption on the surface of OA particles. No significant hygroscopic growth or deliquescence behavior for OA is observed in the 5-90\% RH range studied, consistent with previous studies by EDB and other methods (Peng et al., 2001; Brooks et al., 2002; Braban et al., 2003; Ma et al., 2013). Theory prediction and bulk measurements also show the deliquescence point of OA is greater than $97 \%$ RH (Peng et al., 2001; Zamora et al., 2011). Measurements using the HTDMA in early studies indicated substantial water uptake by OA particles during hydration above $45 \%$ RH (Prenni et al., 2001; Mikhailov et al., 2009). The phase state of the particles can strongly influence their hygroscopic growth. Mikhailov et al. (2009) demonstrated that initial state of OA particles generated in their measurement should be amorphous, resulting in gradual water uptake at lower RH. OA particles generated in the present study may be crystalline due to dry conditions and electric charge effects (Mikhailov et al., 2009), thus accounting for no significant water uptake prior to deliquescence point. Although OA has a high vapor pressure, no evaporation losses for OA particles are observed in agreement with earlier HTDMA studies, suggesting that the initial particles under dry conditions consisted of OA dihydrate or nonstoichiometric hydrates containing about two water molecules per oxalic acid molecule 

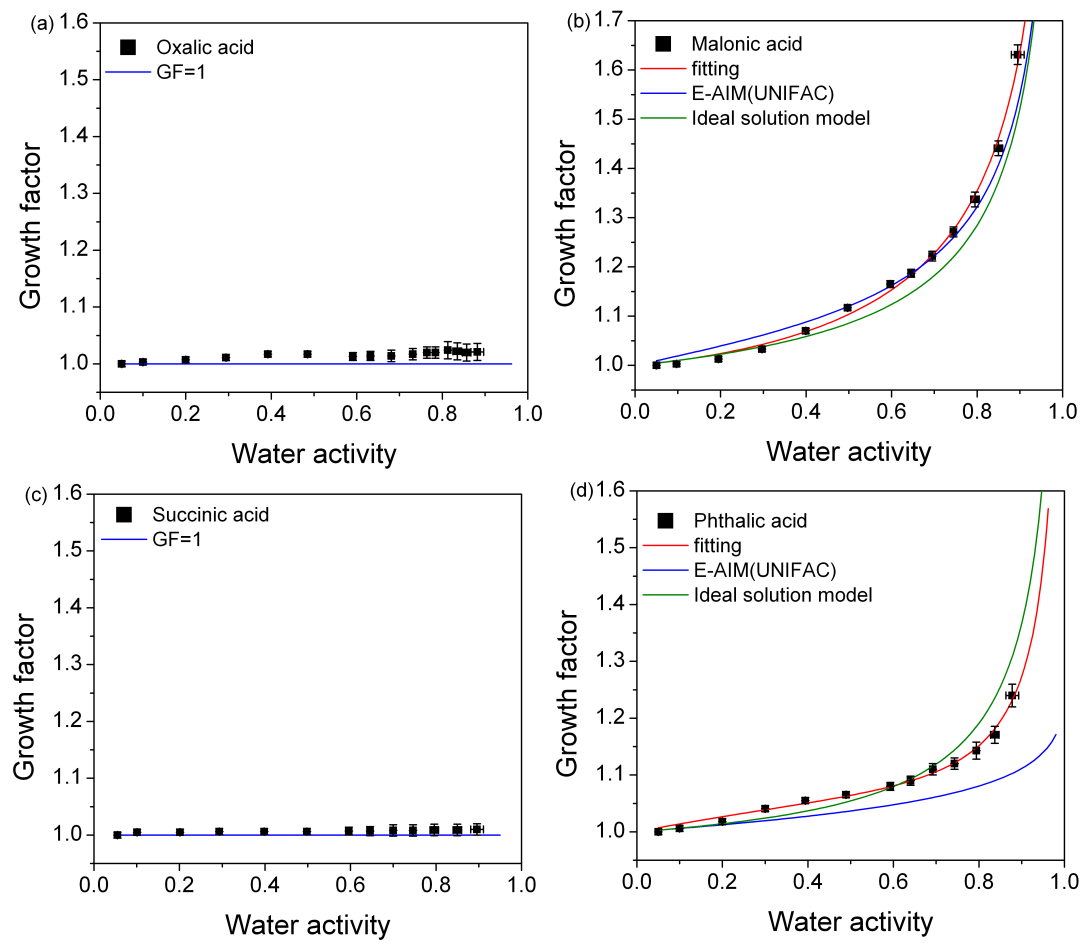

Figure 2. Hygroscopic growth factors of (a) oxalic acid, (b) malonic acid, (c) succinic acid, and (d) phthalic acid particles as a function of water activity. Initial particle diameter is about $100 \mathrm{~nm}$. For malonic acid and phthalic acid, the fit to the measurements with Eq. (2) is shown. Predictions from the E-AIM (UNIFAC) and ideal solution model are also included. The uncertainty in our measured growth factors is within 0.02 .

(Prenni et al., 2001; Mikhailov et al., 2009). It has been found that crystalline anhydrous OA particles could transform into crystalline OA dihydrate during hydration between 10 and $30 \% \mathrm{RH}$ (Braban et al., 2003). If the initial particles are composed of crystalline anhydrous OA, then the GF of around 1.17 can be obtained based on the transition from anhydrous form to a dihydrate form. Obviously, this is not the case in the present study.

As shown in Fig. 2b, MA exhibits continuous water uptake with increasing RH and no phase transition is observed, in agreement with previous EDB and HTDMA measurements (Peng et al., 2001; Prenni et al., 2001). Such hygroscopic behavior indicates MA particles are in a liquid state and still retain some water even at $\mathrm{RH} \sim 5 \%$ (Peng et al., 2001). Predictions from UNIFAC model based on liquid MA assumption have a good agreement with measured GF above $50 \% \mathrm{RH}$ while slightly overestimating hygroscopic growth at lower RH. Contrarily, the ideal solution model underestimates the hygroscopic growth of MA above $40 \% \mathrm{RH}$. As for SA (Fig. 2c), no hygroscopic growth is observed even at $90 \%$ RH, which was also reported by Prenni et al. (2001) and Svenningsson et al. (2006). According to EDB and bulk measurements, the deliquescence relative humidity (DRH) of crystalline SA can reach up to $99 \% \mathrm{RH}$ due to its limited solubility (Peng et al., 2001; Zamora et al., 2011). The hygroscopic growth of submicron PA particles is given in Fig. 2d. The PA particles take up water gradually without phase changes in the RH range studied. Our results suggest initial PA particles may still retain water at the lowest RH, similar to other organic species, such as citric acid and malic acid (Peng et al., 2001). The overall trend of the growth curve is consistent with measurements reported by Brooks et al. (2004) and Hartz et al. (2006). Considering the molecular structure of PA, the UNIFAC model with the parameters modified by Peng et al. (2001) was used here. The UNIFAC model underestimates hygroscopic growth at the moderate and high $\mathrm{RH}$, while predictions from ideal solution model are close to the measured GFs. It should be noted that Peng et al. (2001) corrected the UNIFAC model interaction parameters only based on water activity data for solutions of seven dicarboxylic acids, mainly straight chain carboxylic acids. Therefore, more water activity data for complex model organic compounds may be helpful for further UNIFAC parameter modification.

\subsection{Hygroscopic growth of multicomponent organic aerosols}

For organic aerosols containing OA, theoretical growth curves derived from E-AIM are based on various OA phase assumptions, i.e., crystalline and liquid phase, indicated by 

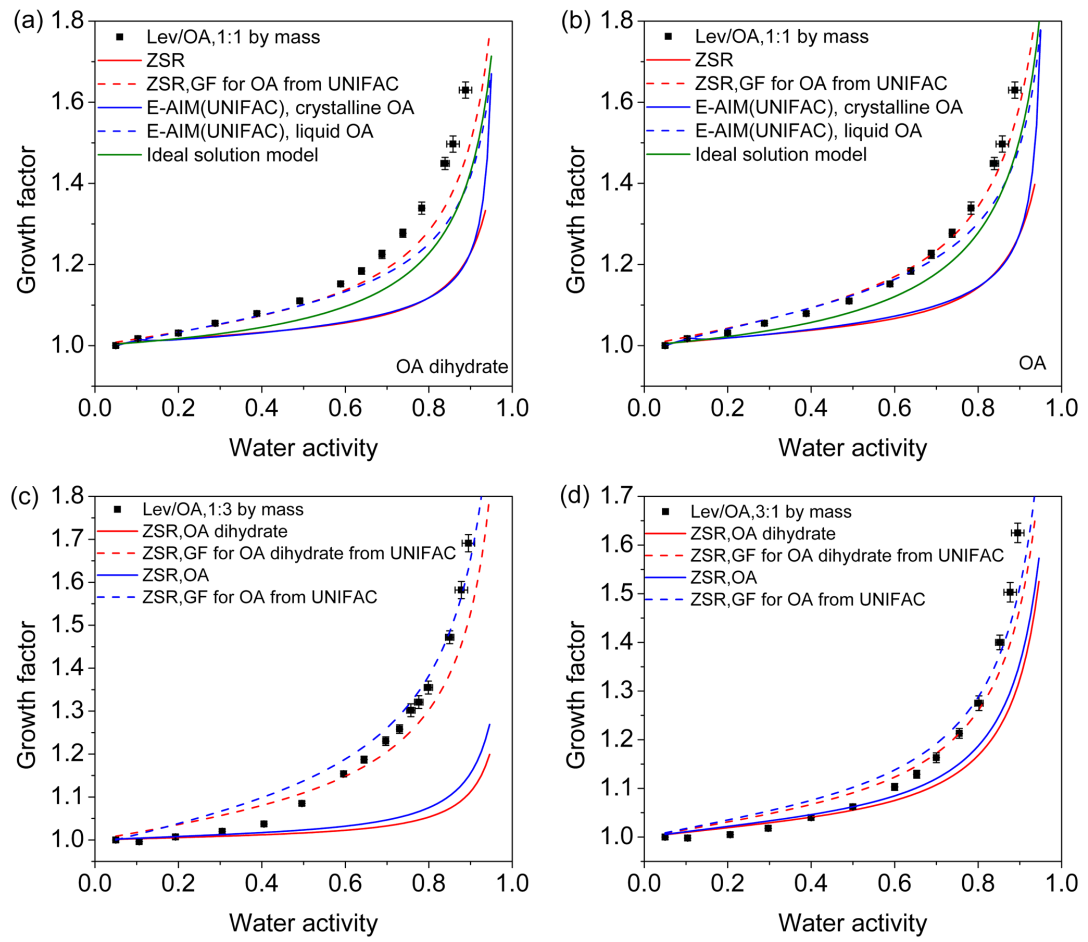

Figure 3. Hygroscopic growth factors of aerosols containing levoglucosan and oxalic acid (Lev / OA) with various mass ratio (a) and (b) $1: 1$, (c) $1: 3$, (d) $3: 1$ as a function of water activity. Initial particle diameter is about $100 \mathrm{~nm}$. Predictions from the ZSR, E-AIM (UNIFAC), and ideal solution model are included in (a) and (b), assuming oxalic acid dihydrate and anhydrous oxalic acid in the initial particles under dry conditions, respectively. The dashed lines are calculated based on liquid oxalic acid (OA) assumption. For (c) $1: 3$, (d) $3: 1$ mass ratio, only ZSR-predicted curves are shown on the basis of different OA assumption. The uncertainty in our measured growth factors is within 0.02 .

solid and dashed lines, respectively. In the ZSR approach, the GFs of OA in a crystalline phase are set equal to 1 and the hygroscopic growth curve of $\mathrm{OA}$ in a liquid phase is obtained from the UNIFAC model (i.e., dehydration curve, which is highly consistent with measured growth curve for OA dihydrate at high RH by Mikhailov et al., 2009). To better reproduce the measured GFs, model calculations assuming crystalline or liquid OA dihydrate and crystalline or liquid anhydrous OA are presented in Figs. 3a, 6a, 7a, 9a and 3b, 6b, 7b, $9 b$.

\subsubsection{Levoglucosan and oxalic acid (Lev / OA)}

The hygroscopic behaviors of organic aerosols containing levoglucosan and OA at different mass ratios are shown in Fig. 3. For the 1:1 mixed Lev / OA particles (Fig. 3a, b), no deliquescence behavior is observed and the continuous water uptake starting at low $\mathrm{RH} \sim 10 \%$ indicates the initial particles appear to be in a liquid state and retain some water. Both ZSR relation and E-AIM based on crystalline OA solid phase assumption strongly underestimate the hygroscopic growth of Lev / OA particles in the whole RH range. ZSR approach assumes independent water uptake of components and no interactions exist in the mixtures. Thus, interactions between individual components of mixed particles can determine whether this simple method will deviate from measured GFs for multicomponent aerosols. Measurements with the HTDMA have demonstrated that levoglucosan particles could retain water even at RH lower than $10 \%$ (Mochida and Kawamura, 2004; Mikhailov et al., 2009). The supersaturated levoglucosan solution may inhibit the formation of crystalline OA during the generation of initial particles. Parsons et al. (2004a) also found that levoglucosan could reduce the deliquescence or crystallization relative humidity of ammonium sulfate. Thus, OA in the initial mixed particles may exist in a liquid state and contributes to water uptake by mixed particles in the subsequent humidification (Prenni et al., 2001; Mikhailov et al., 2009), which leads to enhanced hygroscopic growth compared to predictions assuming crystalline solid oxalic acid in the mixture.

As shown in Fig. 3a, water uptake predictions from ZSR relation and E-AIM are obviously elevated, assuming OA exists in the liquid phase over the whole RH range studied. However, differences between measured GFs and predicted values based on liquid OA dihydrate assumption are still outside the measurement uncertainty at high RH above $60 \%$. In the early study by Prenni et al. (2003), it indicated that ZSR rule could well describe the hygroscopic growth of internally mixed particles containing ammonium sulfate and 
oxalic acid based on the liquid dihydrate assumption. The discrepancy in the present study may be caused by the potential interactions between levoglucosan and oxalic acid in the droplets, which may promote the hygroscopicity of particles at high RH. The hydrogen bonding between levoglucosan and oxalic acid may enhance the dissociation of OA at high RH, as suggested by the van 't Hoff factor of $1: 1$ Lev / OA mixture $(i=1.71$ considerably larger than 1 , seen in Fig. 10a). The increasing dissociation of OA could produce more ions at a given $\mathrm{RH}$, leading to reduction of water activity of the Lev / OA droplets (Varga et al., 2007), as indicated by Eq. (6). Considering the relatively humidity is kept constant at a specific value during the measurement, more water vapor from gas phase would condensate on the droplets to promote the water activity for water gas-liquid partitioning equilibrium, as determined by Köhler equation. Consequently, the Lev / OA mixture shows more water uptake compared to model predictions irrespective of OA phase assumption.

Previous HTDMA studies have shown that the submicron oxalic acid particles under dry conditions are most likely composed of amorphous or liquid dihydrate. For example, Prenni et al. (2001) observed continual hygroscopic growth of oxalic acid particles with increasing relative humidity, suggesting the initial particles were not completely dry but rather concentrated solution droplets. They reported that the measured hygroscopic growth agreed well with Köhler model calculations assuming that the initially generated particles consisted of liquid oxalic acid dihydrate. Mikhailov et al. (2009) also found that the solid amorphous oxalic acid particles under dry conditions consisted of oxalic acid dihydrate, as indicated by Köhler model calculations. It can be seen that the submicron oxalic acid particles tend to consist of dihydrate or non-stoichiometric hydrates containing about two water molecules per oxalic acid molecule. In fact, the formation of anhydrous oxalic acid usually requires very dry conditions and cannot be expected in HTDMA measurement (Mikhailov et al., 2009). Although oxalic acid has a high enough vapor pressure, no evaporation losses were observed in previous HTDMA studies (Prenni et al., 2001; Mikhailov et al., 2009), as well as in our study. The most plausible explanation for the high stability of the investigated OA particles is that they were not anhydrous but composed of dihydrate or non-stoichiometric hydrates containing about two water molecules per oxalic acid molecule (Mikhailov et al., 2009). As for $100 \mathrm{~nm}$ levoglucosan / oxalic acid mixed particles, there is also no evaporation losses observed in our study, as indicated by no reduction in particle size during measurements at $\mathrm{RH}<5 \%$. The similar phenomenon was also observed for other mixed systems containing oxalic acid. Thus, it indicates oxalic acid in the submicron mixed particles under dry conditions may also exist as dihydrate or non-stoichiometric hydrates containing about two water molecules per oxalic acid molecule.
For comparison, predicted growth curves from three models according to crystalline or liquid anhydrous OA assumption are given in Fig. 3b. The ZSR method based on OA liquid phase assumption can well describe water uptake of Lev / OA mixtures (1:1, mass) in the 5-90\% RH range. The predictions from E-AIM assuming OA is present in a liquid phase, are close to measured GFs but still lower due to the underestimation for water contents of levoglucosan at high RH (Fig. S2, Supplement). The growth curves from ideal solution model differ from measurements regardless of OA composition assumption, caused by the solution nonideality.

To further explore the effects of composition, the hygroscopic growth of Lev / OA (1:3, 3:1, mass) mixtures with only ZSR predicted curves are shown in Fig. $3 c$, d. In the Lev / OA (1:3, mass) case, it can be observed that predictions based on liquid anhydrous $\mathrm{OA}$ assumption are in good agreement with measured GFs above $70 \% \mathrm{RH}$. Below $40 \% \mathrm{RH}$, the mixed particles show no obvious water uptake and the consistence of measurements with predictions based on OA inert mass assumption suggests $\mathrm{OA}$ in this mixture may exist in amorphous or crystalline solid phase. Levoglucosan in the particles can take up water gradually with increasing $\mathrm{RH}$, resulting in formation of aqueous solution. Amorphous or crystalline solid OA can be partially dissolved in aqueous levoglucosan and contribute to water uptake at medium $40-70 \% \mathrm{RH}$. By comparison with ZSR calculations, it can be concluded that OA finishes full deliquescence after $60 \% \mathrm{RH}$. As for the Lev / OA (3:1, mass) case, it can be seen that the discrepancies between measurements and predictions based on liquid dihydrate assumption decrease at high RH compared to those for other mixing ratios due to the minor oxalic acid composition. Previous studies on aerosol particles containing binary components indicated that organic species, such as malonic acid and citric acid, contributing to water uptake at low RH could induce partial deliquescence of ammonium sulfate and lower its deliquescence point (Choi and Chan, 2002b; Prenni et al., 2003; Zardini et al., 2008). Svenningsson et al. (2006) have investigated the hygroscopic growth of organic mixtures composed of levoglucosan, succinic acid, and fulvic acid and found that experimental values could be reproduced by ZSR approach as long as limited solubility of succinic acid was taken into consideration.

Infrared spectra of equal mass levoglucosan and oxalic acid mixture are used to confirm the interactions between species and phase behaviors during hydration. The ATR-IR spectra of pure levoglucosan, OA particles, and Lev / OA ( $1: 1$, mass) mixture recorded at various RHs are presented in Fig. 4. For levoglucosan aerosols, the spectrum at $2 \% \mathrm{RH}$ shows a broad absorption between 3570 and $3050 \mathrm{~cm}^{-1}$ assigned to $\mathrm{O}-\mathrm{H}$ stretch. The absorbance of the $\mathrm{O}-\mathrm{H}$ stretch increases at higher RH and a new infrared feature occurs at $1646 \mathrm{~cm}^{-1}$ contributed by condensed phase water. The spectrum of OA particles at $2 \% \mathrm{RH}$ shows an anhydrous feature with a sharp carbonyl stretching band at $1723 \mathrm{~cm}^{-1}$. When 

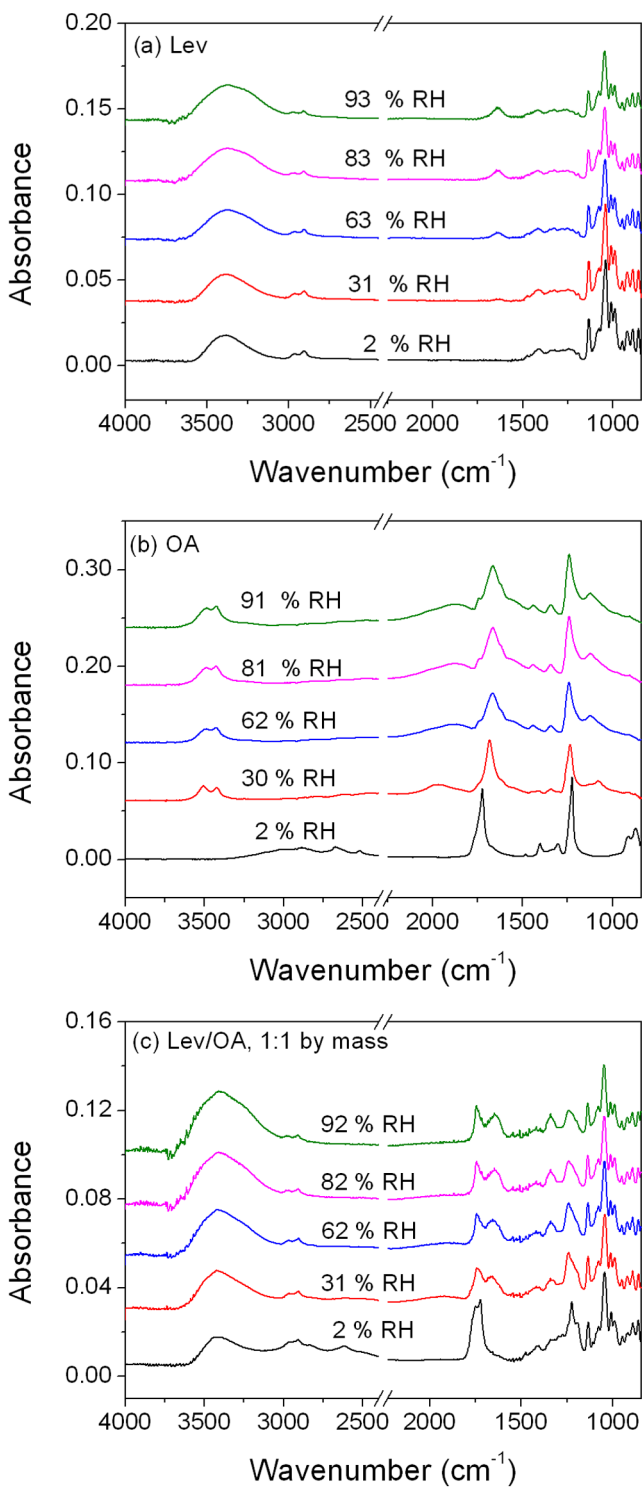

Figure 4. ATR-FTIR absorbance spectra of aerosol particles upon hydration with RH for (a) levoglucosan, (b) oxalic acid, and (c) levoglucosan/oxalic acid mixture ( $1: 1$, by mass). Features from gasphase water have been subtracted. Gas-phase $\mathrm{CO}_{2}$ absorptions have been removed and the spectra have been offset for clarity.

$\mathrm{RH}$ increases to $30 \%$, the twin bands in the region 3600 $3300 \mathrm{~cm}^{-1}$ indicate the transformation of anhydrous crystalline form to dihydrate one. No obvious liquid water feature can be observed with further humidification up to $91 \% \mathrm{RH}$. Our infrared measurement for OA particles is consistent with observation by Braban et al. (2003) while it deviates from the H-TDMA results in Fig. 2a. This may be caused by the size effect considering the IR absorption in the present study is mainly contributed by larger micron particles. As with the Lev / OA (1:1, mass) mixture, features from both levoglucosan and OA components are present. In the $2 \% \mathrm{RH}$ spec-

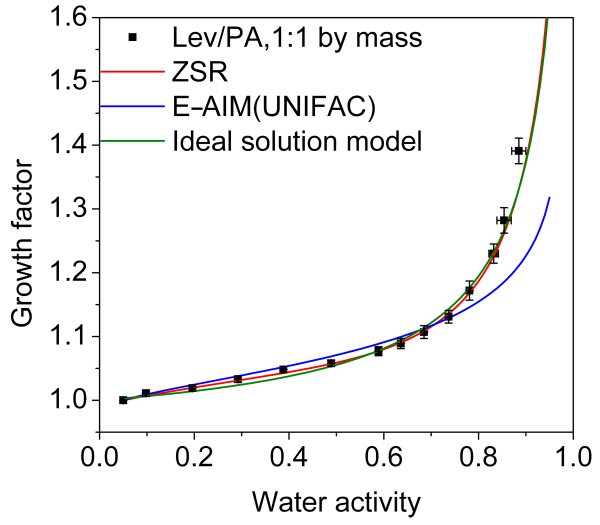

Figure 5. Hygroscopic growth factors of aerosols consisting of levoglucosan and phthalic acid (Lev / PA) at a mass ratio of $1: 1$ as a function of water activity. Initial particle diameter is about $100 \mathrm{~nm}$. Predictions based on the ZSR, E-AIM (UNIFAC), and ideal solution model are also included. The uncertainty in our measured growth factors is within 0.02 .

trum the carbonyl stretching band from OA is split into peaks at 1750 and $1724 \mathrm{~cm}^{-1}$, which suggests strong interaction between OA and levoglucosan. The carbonyl stretching band at $1750 \mathrm{~cm}^{-1}$ is close to that in the liquid phase, indicating the Lev / OA (1:1, mass) mixture appears to be at least partially in a liquid-like phase. The spectra in Fig. $4 c$ were recorded with larger particles, thus crystallization would be even less likely within smaller particles used in the HTDMA experiments, suggesting that mixtures of oxalic acid and levoglucosan may be in the liquid or amorphous solid state even at the lowest RHs studied. Above $30 \% \mathrm{RH}$, the carbonyl stretching band shifts to $1743 \mathrm{~cm}^{-1}$ in agreement with the $\mathrm{C}=\mathrm{O}$ feature from aqueous $\mathrm{OA}$ (Hug and Bahnemann, 2006). Meanwhile, the increase of absorption between 3570 and $3050 \mathrm{~cm}^{-1}$ and feature at $1646 \mathrm{~cm}^{-1}$ confirm obvious water uptake by mixture particles. The IR results also indicate levoglucosan could strongly influence the phase state of $\mathrm{OA}$, resulting in more water uptake at low $\mathrm{RH}$.

\subsubsection{Levoglucosan and phthalic acid (Lev / PA)}

Figure 5 shows the hygroscopic growth of $100 \mathrm{~nm}$ initial particles containing levoglucosan and phthalic acid with equal mass ratio. Continuous water uptake without a phase transition can be observed. Both the ZSR and ideal solution model could well describe the hygroscopic behavior of this mixture within experiment uncertainty, indicating that the droplets behave like ideal solution. The E-AIM (UNIFAC) underestimates water uptake at high $\mathrm{RH}$ due to strong interactions between polar groups on the solute molecule (Peng et al., 2001). Choi and Chan (2002a) used the EDB to measure the water activity of binary organic mixtures by equal molar ratio including maleic acid / malic acid and malonic acid / glutaric acid. They found that both ZSR and the modified UNIFAC 

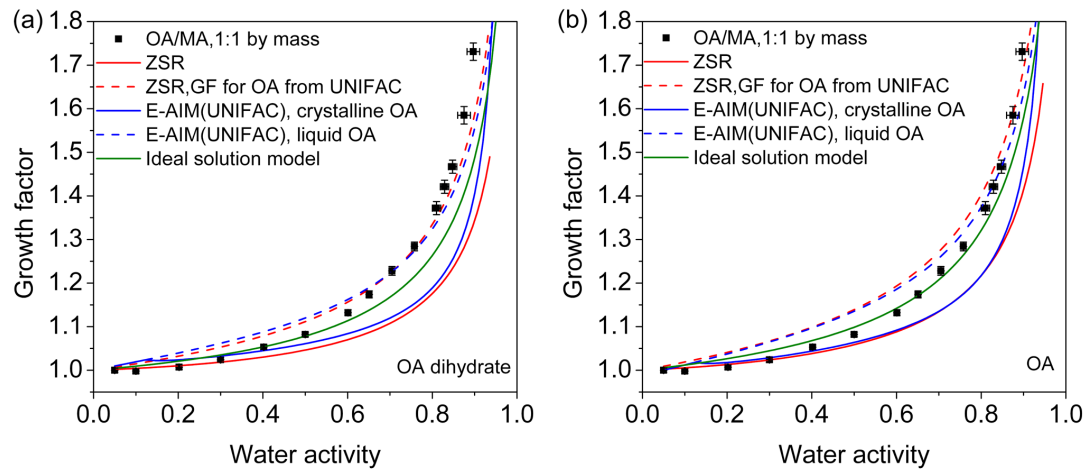

Figure 6. Hygroscopic growth factors of aerosols containing oxalic acid and malonic acid (OA / MA) at a mass ratio of $1: 1$ as a function of water activity. Initial particle diameter is about $100 \mathrm{~nm}$. Predictions from the ZSR, E-AIM (UNIFAC), and ideal solution model are also included, assuming (a) oxalic acid dihydrate and (b) anhydrous oxalic acid in the initial particles under dry conditions. The dashed lines are calculated based on liquid oxalic acid (OA) assumption. The uncertainty in our measured growth factors is within 0.02 .
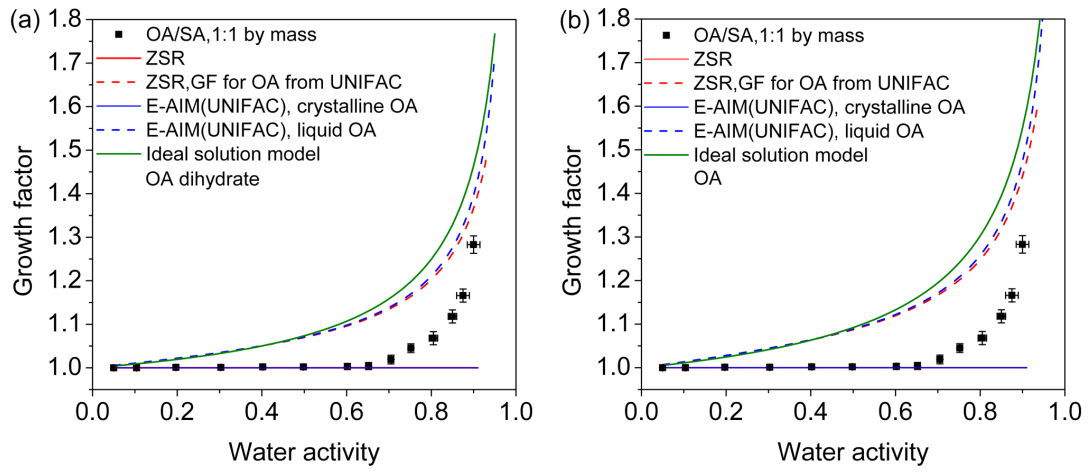

Figure 7. Hygroscopic growth factors of aerosols consisting of oxalic acid and succinic acid (OA / SA) at a mass ratio of $1: 1$ as a function of water activity. Initial particle diameter is about $100 \mathrm{~nm}$. Predictions from the ZSR, E-AIM (UNIFAC), and ideal solution model are also included, assuming (a) oxalic acid dihydrate and (b) anhydrous oxalic acid in the initial particles under dry conditions. The dashed lines are calculated based on liquid oxalic acid (OA) assumption. The uncertainty in our measured growth factors is within 0.02 .

could accurately predict the measurements for these mixtures which did not experience phase transition, similar to results observed with the HTDMA by Moore and Raymond (2008).

\subsubsection{Oxalic acid and malonic acid (OA / MA)}

Figure 6 shows the hygroscopic growth of $100 \mathrm{~nm}$ initial particles containing oxalic acid and malonic acid with equal mass ratio. The hygroscopic growth of OA / MA (1:1, mass) mixed particles displays a smooth nature. Previous particle measurements showed that MA could strongly affect the deliquescence behavior of coexisting species like ammonium sulfate or glutaric acid (Choi and Chan, 2002a; Ling and Chan, 2008). It was reported that MA could substantially suppress the crystallization of glutaric acid in the equal molar mixed particles (Choi and Chan, 2002a). Due to the influence of MA, the OA may also exist in a liquid state at low RH thus the mixed particles still contain some water retained from these two components and take up water continuously from low RH. Assuming the oxalic acid in the initial particles com- posed of dihydrate, predictions from ZSR and E-AIM based on OA liquid phase assumption are relatively consistent with measured hygroscopic growth while deviating a lot based on crystalline solid assumption (Fig. 6a). As for the anhydrous OA case, the deviations between predictions from ZSR and E-AIM, based on OA liquid phase assumption and measurements, increase at low RH while minimize at high $\mathrm{RH}$, and the growth curve from ideal solution model is more close to the experiment data.

\subsubsection{Oxalic acid and succinic acid (OA / SA)}

Figure 7 displays the hygroscopic behavior of $100 \mathrm{~nm}$ initial particles containing oxalic acid and succinic acid with equal mass ratio. Based on ZSR assumption, it can be expected that no water uptake by this mixture would occur over the RH range studied, as indicated by ZSR-calculated curve. However, the obvious hygroscopic growth of OA / SA mixture after $70 \%$ RH can be observed and the GF is up to 1.28 at $90 \% \mathrm{RH}$. No model curves are in good agreement 
with experiment results within measurement uncertainty in the entire RH range. The predicted DRH from the modified UNIFAC model is $96 \%$ RH for equal mass OA / SA mixture. The ATR-IR spectra of micron mixed particles during hydration also suggest no water uptake below $92 \% \mathrm{RH}$ (seen in Fig. 8). However, the submicron OA / SA mixed particles present continuous growth without distinct deliquescence transition from $70 \% \mathrm{RH}$. SA has been proved to be nonhygroscopic under subsaturation condition by various measurement methods. The water uptake by the submicron OA / SA mixed particles may be attributed to OA which may form amorphous rather than crystalline phase in the initial mixed particles with submicron size (Mikhailov et al., 2009). The amorphous OA tends to take up water at lower RH than its crystalline counterpart thus contributing to the gradual hygroscopic growth of OA / SA mixed particles below DRH, which could not be predicted by thermodynamic methods.

Infrared spectra of equal mass oxalic acid and succinic acid mixture are used to explore the hygroscopic behaviors. The ATR-IR spectra of pure OA, SA particles, and OA / SA ( $1: 1$, mass) mixture recorded at various RHs are presented in Fig. 8. For pure SA aerosols, the spectra at various RHs show no difference, and no liquid water feature can be observed. In the spectra of OA / SA (1:1, mass) mixture, the occurrence of absorption in the region $3600-3300 \mathrm{~cm}^{-1}$ indicates the transformation of anhydrous form to dihydrate. However, no obvious condensed phase water feature is detected even at $90 \%$ RH. The difference between HTDMA and IR measurements may be caused by size effects which have an influence on the hygroscopic behaviors of aerosols (Laskina et al., 2015; Cheng et al., 2015).

\subsubsection{Oxalic acid and phthalic acid (OA / PA)}

Figure 9 shows the hygroscopic growth of $100 \mathrm{~nm}$ initial particles containing oxalic acid and phthalic acid with equal mass ratio. Although PA is less hygroscopic than MA, the OA / PA mixed particles show a similar growth trend with that of OA / MA. It is obvious that the ZSR and E-AIM substantially underestimate the water content of particles at medium and high RH without taking the deliquescence of OA into account. Due to the presence of hygroscopic species such as phthalic acid, the crystallization of OA in the mixed particles could be suppressed during the drying process leading to OA in a liquid or amorphous state in the initial particles. Thus, oxalic acid could contribute to water uptake by mixed particles from low RH (Hemming and Seinfeld, 2001), resulting in enhanced hygroscopic growth compared to predictions assuming crystalline solid oxalic acid in the mixture. We also measured hygroscopic growth of aerosols consisting of levoglucosan, oxalic acid, and phthalic acid (Lev / OA / PA) with equal mass ratio and found the similar hygroscopic behavior with Lev / OA or OA / PA mixtures, shown in Fig. S3 in the Supplement.
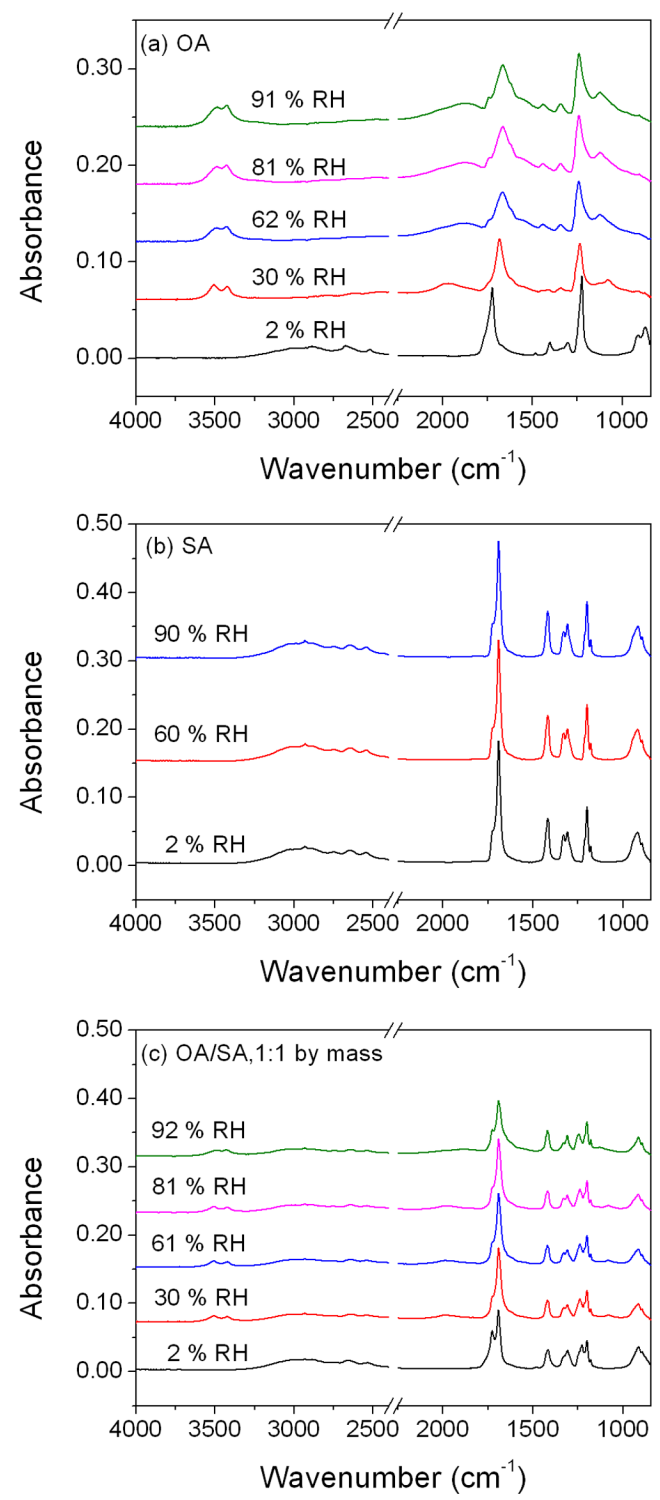

Figure 8. ATR-FTIR absorbance spectra of aerosol particles upon hydration with RH for (a) oxalic acid, (b) succinic acid, and (c) oxalic acid/succinic acid mixture ( $1: 1$, by mass). Features from gasphase water have been subtracted. Gas-phase $\mathrm{CO}_{2}$ absorptions have been removed and the spectra have been offset for clarity.

\subsection{Evaluation of organic droplet nonideality}

To describe the dissociation and nonideality of submicron organic aerosol droplets, the van 't Hoff factor $i$ is used to assess the degree of deviation from ideality. For the organics, a van 't Hoff factor of 1 usually suggests that the solution behaves as an ideal solution. Based on the Eq. (6), van 't Hoff factor $i$ is obtained from the slope of the linear fit by $a_{\mathrm{w}}^{-1}$ versus $n_{\mathrm{s}} / n_{\mathrm{w}}$ for each aerosol droplet. The calculated van 't Hoff factor $i$ as well as corresponding $R^{2}$ values are given in Fig. 10. For mixtures containing oxalic acid, van 't Hoff 

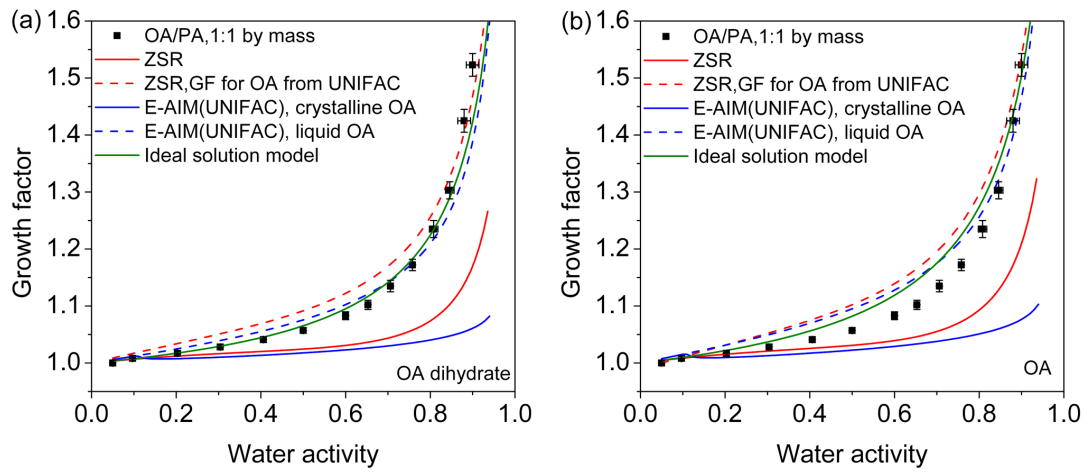

Figure 9. Hygroscopic growth factors of aerosols consisting of oxalic acid and phthalic acid (OA / PA) at a mass ratio of $1: 1$ as a function of water activity. Initial particle diameter is about $100 \mathrm{~nm}$. Predictions from the ZSR, E-AIM (UNIFAC), and ideal solution model are also included, assuming (a) oxalic acid dihydrate and (b) anhydrous oxalic acid in the initial particles under dry conditions. The dashed lines are calculated based on liquid oxalic acid (OA) assumption. The uncertainty in our measured growth factors is within 0.02 .
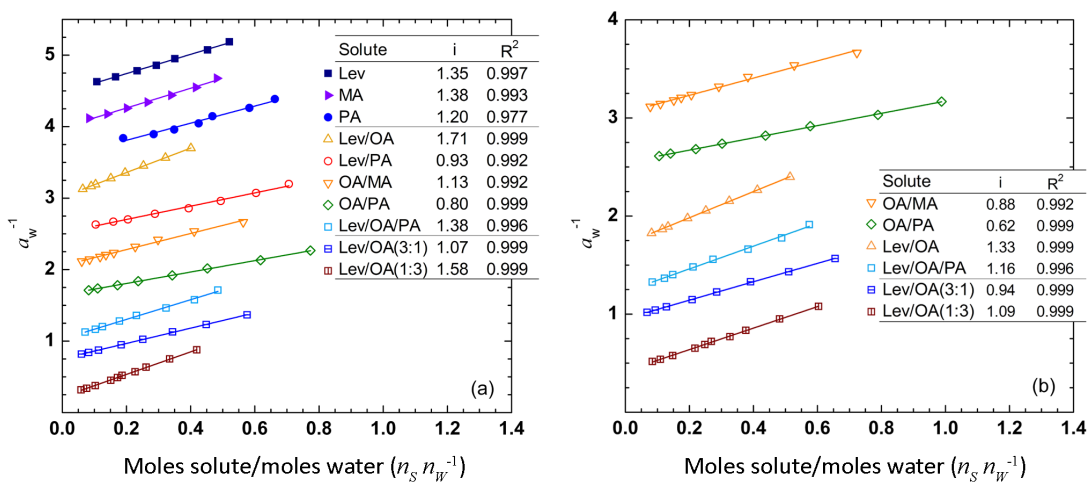

Figure 10. The inverse of the water activity $\left(a_{\mathrm{W}}^{-1}\right)$ as a function of the ratio of mole number of total solute to mole number of water $\left(n_{\mathrm{S}} / n_{\mathrm{W}}\right)$ for all organic droplets. The slope of the fit line is equal to the van 't Hoff factor $(i)$. The $R^{2}$ values for the fit are also listed. Each data set was offset by $a_{\mathrm{W}}^{-1}=0.3$ from the previous data set for clarity. Calculations for aerosols containing oxalic acid are based on assumption of (a) oxalic acid dihydrate and (b) anhydrous oxalic acid. All the mixtures have equal mass composition except specially noted.

factor $i$ is calculated based on various OA composition in initial particles, OA dihydrate, and anhydrous OA, shown in Fig. 10a and b, respectively.

The van 't Hoff factors for OA, SA, and their mixture are not included since no full deliquescence occurs in the measured $\mathrm{RH}$ range. The resulting $i$ for levoglucosan, MA, and $\mathrm{PA}$ is $1.35,1.38$, and 1.20 , respectively, consistent with the literature values of 1.05 and 1.29 for levoglucosan (Zamora and Jacobson, 2013; Mikhailov et al., 2009), and 1.37 for MA (Wise et al., 2003). It seems that the three singlecomponent aerosol droplets deviate slightly from ideal solution. Assuming OA dihydrate, $i$, for most organic mixtures is close to 1, while for Lev / OA with the mass ratio of $1: 1$, $1: 3$, it is considerably larger than 1 , suggesting that the mixtures deviate substantially from an ideal solution. For the anhydrous OA assumption case, only $i(0.62)$ for OA / PA mixture deviates a lot from 1 . In the case of Lev / OA ( $1: 1$, $1: 3$ by mass), $i$ for mixtures assuming OA dihydrate is 1.71 and 1.58, respectively, larger than that of the pure component (e.g., $i$ for OA dihydrate is 0.98; Mikhailov et al., 2009).

\subsection{CCN activity of multicomponent WSOC aerosols}

Previous studies have confirmed organics may play important role in cloud formation by acting as cloud condensation nuclei (CCN) (Suda et al., 2014; Xu et al., 2014). Here, we use the single hygroscopicity parameter $\kappa$ to evaluate the hygroscopicity and CCN activity of WSOC aerosol particles (Petters and Kreidenweis, 2007). This parameter usually can be derived from hygroscopic growth measurements at RH $\sim 90 \%$ with the HTDMA or from critical supersaturation measurements under supersaturated conditions (Petters and Kreidenweis, 2007). It has been shown that $\kappa$ values estimated from the two methods agree well within $30 \%$, especially for organics with continuous hygroscopic growth (Petters and Kreidenweis, 2007; Chan et al., 2008; Petters et al., 2009). For aerosol particles containing OA, it is convenient 


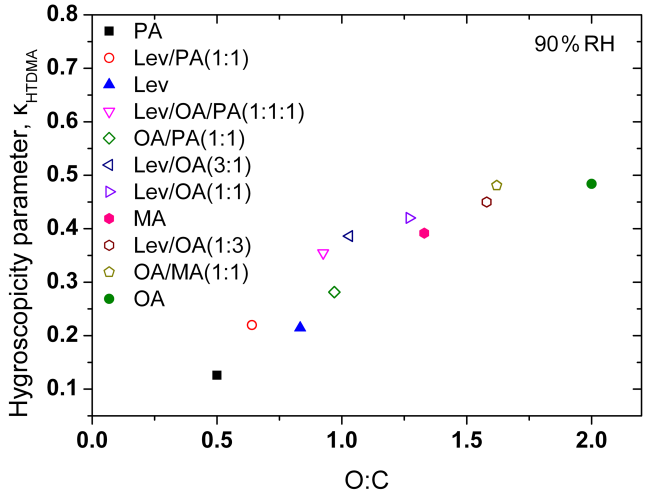

Figure 11. Relationship between $\mathrm{O}: \mathrm{C}$ and hygroscopicity parameter $\kappa$ derived from HTDMA measurements at $90 \% \mathrm{RH}$ for all the organic aerosol particles in this study.

to use the $\kappa$ capturing all solute properties to describe the hygroscopicity without taking OA composition assumption into account, as indicated by Eq. (7).

It has been found that $\kappa$ for organic aerosols may correlate with the ratio of oxygen to carbon atoms $(\mathrm{O} / \mathrm{C})$ in dry particles while deviations from this relationship were also reported (Jimenez et al., 2009; Duplissy et al., 2011; Rickards et al., 2013). The single hygroscopicity parameter $\kappa$ evaluated from the HTDMA data at $90 \% \mathrm{RH}$ is plotted as a function of $\mathrm{O} / \mathrm{C}$ ratio, seen in Fig. 11. The $\kappa$ values for SA and its mixture with OA are not included. For OA, the $\kappa$ value (0.484) is obtained from UNIFAC-predicted GF, consistent with literature values 0.48, 0.504 (Rickards et al., 2013; Kreidenweis et al., 2008). The $\kappa$ values for other pure components are also in good agreement with reported values. As shown in Fig. 11, the general trend indicates the possible relationship between $\kappa$ value and $\mathrm{O} / \mathrm{C}$ ratio for WSOC aerosols. To further assess the effects of coexisting species on hygroscopicity of mixed particles, the $\kappa$ values derived from HTDMA measurements for pure levoglucosan, oxalic acid, and their mixtures at various mass ratios, as well as the corresponding ZSR predictions assuming anhydrous OA or OA dihydrate in a liquid state, are shown in Fig. 12. It can be observed that the hygroscopicity of three Lev / OA mixtures is similar and more close to that of OA compared to levoglucosan. Predictions from ZSR rule significantly underestimate $\kappa$ values derived from GF measurements, regardless of OA composition assumption. The enhanced hygroscopicity of Lev / OA mixed particles is likely due to the fact that the decreasing water activity of droplets resulting from interactions between levoglucosan and oxalic acid controls the water condensation on the droplets. The similar enhancement effects on the hygroscopicity were also observed in aerosol particles containing ammonium sulfate and fulvic acid due to complex chemical interactions (Chan and Chan, 2003).

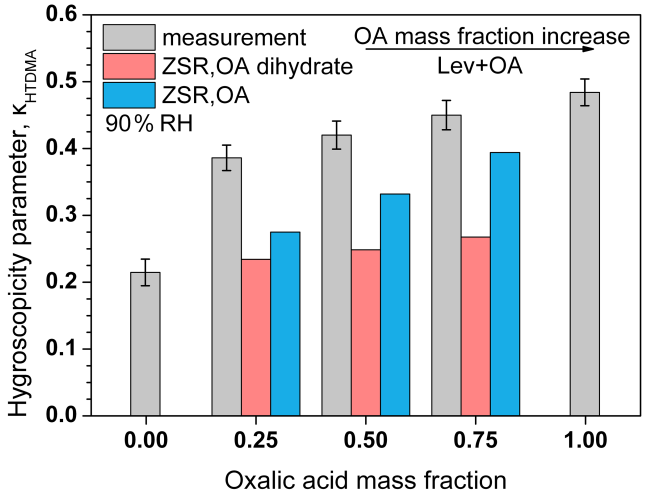

Figure 12. The $\kappa$ results derived from HTDMA measurements at $90 \% \mathrm{RH}$ for aerosols containing oxalic acid (OA) and levoglucosan (Lev) in varying mass proportions. ZSR-predicted $\kappa$ values are also shown by assuming liquid oxalic acid dihydrate or liquid anhydrous oxalic acid in the initial mixtures under dry conditions. The $\kappa$ value of oxalic acid is obtained from the UNIFAC.

\subsection{Effect of organic mixture on hygroscopicity of ammonium sulfate (AS)}

The organic mixture of oxalic acid with levoglucosan is selected to determine the influences of multicomponent organics on the hygroscopic properties of ammonium sulfate (AS). As shown in Fig. 13, the hygroscopic growth measurements for equal mass mixture of AS with OA are also presented for comparison. It can be seen that 1:1 AS / OA mixture does not show any hygroscopic growth until reaching its deliquescence point $77 \% \mathrm{RH}$ consistent with literature values for eutonic mixtures (Brooks et al., 2002). Based on crystalline OA dihydrate assumption, the E-AIM predictions agree well with measured growth factors. It should be noted that the deliquescence point predicted by E-AIM is $73 \%$ RH slightly lower than the experiment result. The ZSR relation underestimates water uptake of AS / OA mixture after complete deliquescence without taking OA dissolution into consideration.

For the 2:1:1 AS / OA / Lev mixed aerosols, the continual hygroscopic growth can be observed without obvious phase transitions. Both E-AIM and ZSR method underestimate the hygroscopic growth above $30 \% \mathrm{RH}$. In the previous study, the binary mixture containing AS and levoglucosan still showed phase transitions even when organic fraction accounted for up to $50 \%$ (Lei et al., 2014). A possible explanation for the present phenomenon is that levoglucosan could suppress crystallization of OA resulting in more water uptake at low RH which enhances partial dissolution of AS. For both equal mass mixtures of AS / OA and AS / Lev, the hygroscopic growth of particles can be well described by EAIM (seen in Fig. 13a and Lei et al., 2014). However, this is not the case for AS / OA / Lev mixture. It is clear that the organic mixture has more complex effects on the hygroscopicity of ammonium sulfate than single organic species. Al- 

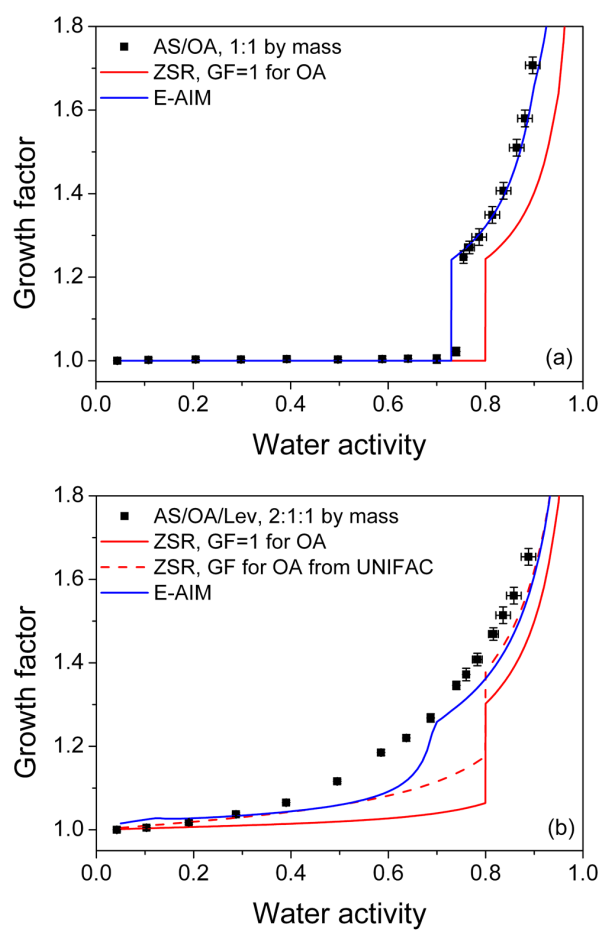

Figure 13. Hygroscopic growth factors of $1: 1$ AS / OA (a), $2: 1: 1$ AS / OA / Lev (b) as a function of water activity. Initial particle diameter is about $100 \mathrm{~nm}$. Predicted growth curves from the ZSR and E-AIM assuming oxalic acid dihydrate are indicated by red and blue lines, respectively. The uncertainty in our measured growth factors is within 0.02 .

though levoglucosan only accounts for a small fraction in the mixture, it still strongly influences the hygroscopic behavior of AS by changing phase state of OA which plays the role of "intermediate" species.

\section{Conclusion and Atmospheric Implications}

In this study, the hygroscopic properties of single-component and multicomponent water-soluble organic compounds mainly involving oxalic acid are investigated with the HTDMA. The hygroscopic behavior of oxalic acid in our measurements differs from previous HTDMA data but agrees with EDB and other methods results. The hygroscopic growth of other single-component aerosol particles including levoglucosan, malonic acid, succinic acid, and phthalic acid, are in good agreement with previous studies. The most of multicomponent organic aerosols show continuous water uptake behavior without obvious phase transition from low $\mathrm{RH}$ except for the OA / SA mixture. For equal mass mixed organic aerosols containing oxalic acid, the coexisting hygroscopic species such as levoglucosan, malonic acid, and phthalic acid have strong influence on the phase behavior of oxalic acid, even suppressing its crystallization completely during the drying process. Oxalic acid in a liquid or amor- phous state in the initial particles could contribute to water uptake by mixed particles from low RH, which leads to enhanced hygroscopic growth compared to predictions assuming crystalline solid oxalic acid in the mixture. The enhanced water uptake of Lev / OA mixed particles is likely due to the change in water activity of droplets resulting from interactions between levoglucosan and oxalic acid. As for oxalic acid / succinic acid mixed particles, the amorphous OA may be responsible for the unexpected water uptake at high $\mathrm{RH}$ below the DRH.

Model methods including E-AIM (UNIFAC), the ZSR approach, and ideal solution model are used to predict the hygroscopic growth of single-component and multicomponent organic aerosol particles. The discrepancies between measurements and predictions from E-AIM and ZSR approach increase at medium and high $\mathrm{RH}$, assuming the OA in a crystalline solid state. For ZSR method, it can describe the hygroscopic growth of aerosol particles containing $\mathrm{OA}$ in a liquid state at high RH based on anhydrous OA composition assumption except for OA / SA. However, it should be noted that the $\mathrm{OA}$ in the initial submicron particles is more likely to exist in an amorphous or crystalline dihydrate form rather than an anhydrous one. Consequently, the substantial underestimation of hygroscopic growth of Lev / OA mixed particles at high RH by the ZSR relation based on liquid dihydrate assumption may be caused by the chemical interactions such as hydrogen bonding between solutes, also indicated by the van 't Hoff factor $i$ and the single hygroscopicity parameter $\kappa$ value. Comparisons between measurement results and thermodynamic predictions assess the reliability of the aerosol models for predicting hygroscopic properties of atmospheric WSOC with various chemical properties. Predictions from E-AIM (UNIFAC) considerably underestimated water content of some mixed aerosols at high RH, suggesting model parameters may need to be further modified so that it can more reliably predict thermodynamic properties of atmospheric organic aerosols. Due to the low disassociation, the most WSOC mixtures studied have a van 't Hoff factor close to 1, except for Lev / OA (1:1, 1:3 mass), influenced by OA composition assumption. By comparing the single hygroscopicity parameter $\kappa$ values with ZSR predictions, it also indicates the hygroscopicity of mixtures containing oxalic acid and levoglucosan is significantly enhanced under high RH conditions.

These findings suggest that the presence of coexisting hygroscopic species has a great impact on the phase behaviors and hygroscopic growth of oxalic acid which has a high deliquescence point. Organic mixture has more complex effects on the hygroscopicity of ammonium sulfate than single species. Although hygroscopic species such as levoglucosan account for a small fraction in the multicomponent aerosols, they may still strongly influence the hygroscopic behavior of AS by changing phase state of OA which plays the role of "intermediate" species. Considering the abundance of oxalic acid in the atmospheric aerosols, its mixtures 
with hygroscopic species may promote water uptake under high RH conditions and thus affect the cloud condensation nuclei $(\mathrm{CCN})$ activity, optical properties, and chemical reactivity of atmospheric particles.

\section{The Supplement related to this article is available online at doi:10.5194/acp-16-4101-2016-supplement.}

Acknowledgements. This project was supported by the Strategic Priority Research Program (B) of the Chinese Academy of Sciences (Grant No. XDB05010400), and the National Natural Science Foundation of China (Contract No. 41173112, 41175119, 21373026) and 111 project (B07012).

Edited by: A. Bertram

\section{References}

Braban, C. F. and Abbatt, J. P. D.: A study of the phase transition behavior of internally mixed ammonium sulfate - malonic acid aerosols, Atmos. Chem. Phys., 4, 1451-1459, doi:10.5194/acp4-1451-2004, 2004.

Braban, C. F., Carroll, M. F., Styler, S. A., and Abbatt, J. P. D.: Phase transitions of malonic and oxalic acid aerosols, J. Phys. Chem. A, 107, 6594-6602, doi:10.1021/jp034483f, 2003.

Brooks, S. D., Wise, M. E., Cushing, M., and Tolbert, M. A.: Deliquescence behavior of organic/ammonium sulfate aerosol, Geophys. Res. Lett., 29, 1917, doi:10.1029/2002GL014733, 2002.

Brooks, S. D., DeMott, P. J., and Kreidenweis, S. M.: Water uptake by particles containing humic materials and mixtures of humic materials with ammonium sulfate, Atmos. Environ., 38, 18591868, doi:10.1016/j.atmosenv.2004.01.009, 2004.

Cappa, C. D., Lovejoy, E. R., and Ravishankara, A. R.: Evidence for liquid-like and nonideal behavior of a mixture of organic aerosol components, P. Natl. Acad. Sci. USA, 105, 1868718691, doi:10.1073/pnas.0802144105, 2008.

Carrico, C. M., Petters, M. D., Kreidenweis, S. M., Collett, J. L., Jr., Engling, G., and Malm, W. C.: Aerosol hygroscopicity and cloud droplet activation of extracts of filters from biomass burning experiments, J. Geophys. Res.-Atmos., 113, D08206, doi:10.1029/2007JD009274, 2008.

Chan, C. K. and Yao, X.: Air pollution in mega cities in China, Atmos. Environ., 42, 1-42, doi:10.1016/j.atmosenv.2007.09.003, 2008.

Chan, M. N. and Chan, C. K.: Hygroscopic properties of two model humic-like substances and their mixtures with inorganics of atmospheric importance, Environ. Sci. Technol., 37, 5109-5115, doi:10.1021/es034272o, 2003.

Chan, M. N., Choi, M. Y., Ng, N. L., and Chan, C. K.: Hygroscopicity of water-soluble organic compounds in atmospheric aerosols: Amino acids and biomass burning derived organic species, Environ. Sci. Technol., 39, 1555-1562, doi:10.1021/es0495841, 2005.

Chan, M. N., Kreidenweis, S. M., and Chan, C. K.: Measurements of the hygroscopic and deliquescence properties of organic compounds of different solubilities in water and their relationship with cloud condensation nuclei activities, Environ. Sci. Technol., 42, 3602-3608, doi:10.1021/es7023252, 2008.

Chebbi, A. and Carlier, P.: Carboxylic acids in the troposphere, occurrence, sources, and sinks: A review, Atmos. Environ., 30, 4233-4249, doi:10.1016/1352-2310(96)00102-1, 1996.

Cheng, Y., Su, H., Koop, T., Mikhailov, E., and Poeschl, U.: Size dependence of phase transitions in aerosol nanoparticles, Nat. Commun., 6, 5923, doi:10.1038/ncomms6923, 2015.

Choi, M. Y. and Chan, C. K.: Continuous measurements of the water activities of aqueous droplets of water-soluble organic compounds, J. Phys. Chem. A, 106, 4566-4572, doi:10.1021/jp013875o, 2002a.

Choi, M. Y. and Chan, C. K.: The effects of organic species on the hygroscopic behaviors of inorganic aerosols, Environ. Sci. Technol., 36, 2422-2428, doi:10.1021/es0113293, 2002b.

Cruz, C. N. and Pandis, S. N.: Deliquescence and hygroscopic growth of mixed inorganic-organic atmospheric aerosol, Environ. Sci. Technol., 34, 4313-4319, doi:10.1021/es9907109, 2000.

Decesari, S., Facchini, M. C., Fuzzi, S., McFiggans, G. B., Coe, H., and Bower, K. N.: The water-soluble organic component of size-segregated aerosol, cloud water and wet depositions from Jeju Island during ACE-Asia, Atmos. Environ., 39, 211-222, doi:10.1016/j.atmosenv.2004.09.049, 2005.

Decesari, S., Fuzzi, S., Facchini, M. C., Mircea, M., Emblico, L., Cavalli, F., Maenhaut, W., Chi, X., Schkolnik, G., Falkovich, A., Rudich, Y., Claeys, M., Pashynska, V., Vas, G., Kourtchev, I., Vermeylen, R., Hoffer, A., Andreae, M. O., Tagliavini, E., Moretti, F., and Artaxo, P.: Characterization of the organic composition of aerosols from Rondônia, Brazil, during the LBASMOCC 2002 experiment and its representation through model compounds, Atmos. Chem. Phys., 6, 375-402, doi:10.5194/acp6-375-2006, 2006.

Duplissy, J., DeCarlo, P. F., Dommen, J., Alfarra, M. R., Metzger, A., Barmpadimos, I., Prevot, A. S. H., Weingartner, E., Tritscher, T., Gysel, M., Aiken, A. C., Jimenez, J. L., Canagaratna, M. R., Worsnop, D. R., Collins, D. R., Tomlinson, J., and Baltensperger, U.: Relating hygroscopicity and composition of organic aerosol particulate matter, Atmos. Chem. Phys., 11, 11551165, doi:10.5194/acp-11-1155-2011, 2011.

Fredenslund, A., Jones, R. L., and Prausnitz, J. M.: Group-contribution estimation of activity-coefficients in nonideal liquid-mixtures, Aiche J., 21, 1086-1099, doi:10.1002/aic.690210607, 1975.

Fuzzi, S., Decesari, S., Facchini, M. C., Matta, E., Mircea, M., and Tagliavini, E.: A simplified model of the water soluble organic component of atmospheric aerosols, Geophys. Res. Lett., 28, 4079-4082, doi:10.1029/2001g1013418, 2001.

Ghorai, S., Wang, B., Tivanski, A., and Laskin, A.: Hygroscopic properties of internally mixed particles composed of $\mathrm{NaCl}$ and water-soluble organic acids, Environ. Sci. Technol., 48, 2234 2241, doi:10.1021/es404727u, 2014.

Graham, B., Mayol-Bracero, O. L., Guyon, P., Roberts, G. C., Decesari, S., Facchini, M. C., Artaxo, P., Maenhaut, W., Koll, P., and Andreae, M. O.: Water-soluble organic compounds in biomass burning aerosols over Amazonia - 1. Characterization by NMR and GC-MS, J. Geophys. Res.-Atmos., 107, 8047, doi:10.1029/2001jd000336, 2002. 
Gysel, M., Weingartner, E., Nyeki, S., Paulsen, D., Baltensperger, U., Galambos, I., and Kiss, G.: Hygroscopic properties of watersoluble matter and humic-like organics in atmospheric fine aerosol, Atmos. Chem. Phys., 4, 35-50, doi:10.5194/acp-4-352004, 2004.

Hallquist, M., Wenger, J. C., Baltensperger, U., Rudich, Y., Simpson, D., Claeys, M., Dommen, J., Donahue, N. M., George, C., Goldstein, A. H., Hamilton, J. F., Herrmann, H., Hoffmann, T., Iinuma, Y., Jang, M., Jenkin, M. E., Jimenez, J. L., Kiendler-Scharr, A., Maenhaut, W., McFiggans, G., Mentel, Th. F., Monod, A., Prévôt, A. S. H., Seinfeld, J. H., Surratt, J. D., Szmigielski, R., and Wildt, J.: The formation, properties and impact of secondary organic aerosol: current and emerging issues, Atmos. Chem. Phys., 9, 5155-5236, doi:10.5194/acp-9-51552009, 2009.

Hameri, K., Charlson, R., and Hansson, H. C.: Hygroscopic properties of mixed ammonium sulfate and carboxylic acids particles, Aiche J., 48, 1309-1316, doi:10.1002/aic.690480617, 2002.

Hansen, H. K., Rasmussen, P., Fredenslund, A., Schiller, M., and Gmehling, J.: Vapor-liquid-equilibria by UNIFAC group contribution .5. Revision and extension, Ind. Eng. Chem. Res., 30, 2352-2355, doi:10.1021/ie00058a017, 1991.

Hartz, K. E. H., Tischuk, J. E., Chan, M. N., Chan, C. K., Donahue, N. M., and Pandis, S. N.: Cloud condensation nuclei activation of limited solubility organic aerosol, Atmos. Environ., 40, 605-617, doi:10.1016/j.atmosenv.2005.09.076, 2006.

Haywood, J. and Boucher, O.: Estimates of the direct and indirect radiative forcing due to tropospheric aerosols: A review, Rev. Geophys., 38, 513-543, doi:10.1029/1999rg000078, 2000

Hegde, P. and Kawamura, K.: Seasonal variations of water-soluble organic carbon, dicarboxylic acids, ketocarboxylic acids, and $\alpha$ dicarbonyls in Central Himalayan aerosols, Atmos. Chem. Phys., 12, 6645-6665, doi:10.5194/acp-12-6645-2012, 2012.

Hemming, B. L. and Seinfeld, J. H.: On the hygroscopic behavior of atmospheric organic aerosols, Ind. Eng. Chem. Res., 40, 41624171, doi:10.1021/ie0007901, 2001.

Hug, S. J. and Bahnemann, D.: Infrared spectra of oxalate, malonate and succinate adsorbed on the aqueous surface of rutile, anatase and lepidocrocite measured with in situ ATR-FTIR, J. Electron. Spectrosc., 150, 208-219, doi:10.1016/j.elspec.2005.05.006, 2006.

Jimenez, J. L., Canagaratna, M. R., Donahue, N. M., Prevot, A. S., Zhang, Q., Kroll, J. H., DeCarlo, P. F., Allan, J. D., Coe, H., Ng, N. L., Aiken, A. C., Docherty, K. S., Ulbrich, I. M., Grieshop, A. P., Robinson, A. L., Duplissy, J., Smith, J. D., Wilson, K. R., Lanz, V. A., Hueglin, C., Sun, Y. L., Tian, J., Laaksonen, A., Raatikainen, T., Rautiainen, J., Vaattovaara, P., Ehn, M., Kulmala, M., Tomlinson, J. M., Collins, D. R., Cubison, M. J., Dunlea, E. J., Huffman, J. A., Onasch, T. B., Alfarra, M. R., Williams, P. I., Bower, K., Kondo, Y., Schneider, J., Drewnick, F., Borrmann, S., Weimer, S., Demerjian, K., Salcedo, D., Cottrell, L., Griffin, R., Takami, A., Miyoshi, T., Hatakeyama, S., Shimono, A., Sun, J. Y., Zhang, Y. M., Dzepina, K., Kimmel, J. R., Sueper, D., Jayne, J. T., Herndon, S. C., Trimborn, A. M., Williams, L. R., Wood, E. C., Middlebrook, A. M., Kolb, C. E., Baltensperger, U., and Worsnop, D. R.: Evolution of organic aerosols in the atmosphere, Science, 326, 1525-1529, doi:10.1126/science.1180353, 2009.
Kanakidou, M., Seinfeld, J. H., Pandis, S. N., Barnes, I., Dentener, F. J., Facchini, M. C., Van Dingenen, R., Ervens, B., Nenes, A., Nielsen, C. J., Swietlicki, E., Putaud, J. P., Balkanski, Y., Fuzzi, S., Horth, J., Moortgat, G. K., Winterhalter, R., Myhre, C. E. L., Tsigaridis, K., Vignati, E., Stephanou, E. G., and Wilson, J.: Organic aerosol and global climate modelling: a review, Atmos. Chem. Phys., 5, 1053-1123, doi:10.5194/acp-5-1053-2005, 2005.

Kawamura, K., Tachibana, E., Okuzawa, K., Aggarwal, S. G., Kanaya, Y., and Wang, Z. F.: High abundances of water-soluble dicarboxylic acids, ketocarboxylic acids and $\alpha$-dicarbonyls in the mountaintop aerosols over the North China Plain during wheat burning season, Atmos. Chem. Phys., 13, 8285-8302, doi:10.5194/acp-13-8285-2013, 2013.

Kreidenweis, S. M., Koehler, K., DeMott, P. J., Prenni, A. J., Carrico, C., and Ervens, B.: Water activity and activation diameters from hygroscopicity data - Part I: Theory and application to inorganic salts, Atmos. Chem. Phys., 5, 1357-1370, doi:10.5194/acp-5-1357-2005, 2005.

Kreidenweis, S. M., Petters, M. D., and DeMott, P. J.: Singleparameter estimates of aerosol water content, Environ. Res. Lett., 3, 035002, doi:10.1088/1748-9326/3/3/035002, 2008.

Krueger, B. J., Grassian, V. H., Iedema, M. J., Cowin, J. P., and Laskin, A.: Probing heterogeneous chemistry of individual atmospheric particles using scanning electron microscopy and energy-dispersive X-ray analysis, Anal. Chem., 75, 5170-5179, doi:10.1021/ac034455t, 2003.

Kundu, S., Kawamura, K., Andreae, T. W., Hoffer, A., and Andreae, M. O.: Molecular distributions of dicarboxylic acids, ketocarboxylic acids and $\alpha$-dicarbonyls in biomass burning aerosols: implications for photochemical production and degradation in smoke layers, Atmos. Chem. Phys., 10, 2209-2225, doi:10.5194/acp-10-2209-2010, 2010.

Laskina, O., Morris, H. S., Grandquist, J. R., Qiu, Z., Stone, E. A., Tivanski, A. V., and Grassian, V. H.: Size matters in the water uptake and hygroscopic growth of atmospherically relevant multicomponent aerosol particles, J. Phys. Chem. A, 119, 4489-4497, doi:10.1021/jp510268p, 2015.

Lei, T., Zuend, A., Wang, W. G., Zhang, Y. H., and Ge, M. F.: Hygroscopicity of organic compounds from biomass burning and their influence on the water uptake of mixed organic ammonium sulfate aerosols, Atmos. Chem. Phys., 14, 11165-11183, doi:10.5194/acp-14-11165-2014, 2014.

Lightstone, J. M., Onasch, T. B., Imre, D., and Oatis, S.: Deliquescence, efflorescence, and water activity in ammonium nitrate and mixed ammonium nitrate/succinic acid microparticles, J. Phys. Chem. A, 104, 9337-9346, doi:10.1021/jp002137h, 2000.

Ling, T. Y. and Chan, C. K.: Partial crystallization and deliquescence of particles containing ammonium sulfate and dicarboxylic acids, J. Geophys. Res.-Atmos., 113, D14205, doi:10.1029/2008jd009779, 2008.

Liu, Q., Jing, B., Peng, C., Tong, S., Wang, W., and Ge, M.: Hygroscopicity of internally mixed multi-component aerosol particles of atmospheric relevance, Atmos. Environ., 125, 69-77, doi:10.1016/j.atmosenv.2015.11.003, 2016.

Low, R. D.: A generalized equation for the solution effect in droplet growth, J. Atmos. Sci., 26, 608-611, 1969.

Ma, Q., Ma, J., Liu, C., Lai, C., and He, H.: Laboratory study on the hygroscopic behavior of external and internal C-2-C-4 dicar- 
boxylic acid-NaCl mixtures, Environ. Sci. Technol., 47, 1038110388, doi:10.1021/es4023267, 2013.

Malm, W. C. and Kreidenweis, S. M.: The effects of models of aerosol hygroscopicity on the apportionment of extinction, Atmos. Environ., 31, 1965-1976, doi:10.1016/s13522310(96)00355-x, 1997.

Marcolli, C., Luo, B. P., and Peter, T.: Mixing of the organic aerosol fractions: Liquids as the thermodynamically stable phases, J. Phys. Chem. A, 108, 2216-2224, doi:10.1021-/jp0360801, 2004.

Martin, S. T.: Phase transitions of aqueous atmospheric particles, Chem. Rev., 100, 3403-3453, doi:10.1021/cr990034t, 2000.

Mayol-Bracero, O. L.: Water-soluble organic compounds in biomass burning aerosols over Amazonia 2. Apportionment of the chemical composition and importance of the polyacidic fraction, J. Geophys. Res., 107, 8091, doi:10.1029/2001jd000522, 2002.

Mikhailov, E., Vlasenko, S., Martin, S. T., Koop, T., and Pöschl, U.: Amorphous and crystalline aerosol particles interacting with water vapor: conceptual framework and experimental evidence for restructuring, phase transitions and kinetic limitations, Atmos. Chem. Phys., 9, 9491-9522, doi:10.5194/acp-9-9491-2009, 2009.

Minambres, L., Mendez, E., Sanchez, M. N., Castano, F., and Basterretxea, F. J.: Water uptake of internally mixed ammonium sulfate and dicarboxylic acid particles probed by infrared spectroscopy, Atmos. Environ., 70, 108-116, doi:10.1016/j.atmosenv.2013.01.007, 2013.

Mircea, M., Facchini, M. C., Decesari, S., Cavalli, F., Emblico, L., Fuzzi, S., Vestin, A., Rissler, J., Swietlicki, E., Frank, G., Andreae, M. O., Maenhaut, W., Rudich, Y., and Artaxo, P.: Importance of the organic aerosol fraction for modeling aerosol hygroscopic growth and activation: a case study in the Amazon Basin, Atmos. Chem. Phys., 5, 3111-3126, doi:10.5194/acp-53111-2005, 2005.

Mochida, M. and Kawamura, K.: Hygroscopic properties of levoglucosan and related organic compounds characteristic to biomass burning aerosol particles, J. Geophys. Res.-Atmos., 109, D21202, doi:10.1029/2004jd004962, 2004.

Mochida, M., Kawabata, A., Kawamura, K., Hatsushika, H., and Yamazaki, K.: Seasonal variation and origins of dicarboxylic acids in the marine atmosphere over the western North Pacific, J. Geophys. Res.-Atmos., 108, 4193, doi:10.1029/2002jd002355, 2003.

Moore, R. H. and Raymond, T. M.: HTDMA analysis of multicomponent dicarboxylic acid aerosols with comparison to UNIFAC and ZSR, J. Geophys. Res.-Atmos., 113, D04206, doi:10.1029/2007jd008660, 2008.

Pandis, S. N., Wexler, A. S., and Seinfeld, J. H.: Dynamics of tropospheric aerosols, J. Phys. Chem., 99, 9646-9659, doi:10.1021/j100024a003, 1995.

Parsons, M. T., Knopf, D. A., and Bertram, A. K.: Deliquescence and crystallization of ammonium sulfate particles internally mixed with water-soluble organic compounds, J. Phys. Chem. A, 108, 11600-11608, doi:10.1021/jp0462862, 2004a.

Parsons, M. T., Mak, J., Lipetz, S. R., and Bertram, A. K.: Deliquescence of malonic, succinic, glutaric, and adipic acid particles, J. Geophys. Res.-Atmos., 109, D06212, doi:10.1029/2003jd004075, 2004b.
Peckhaus, A., Grass, S., Treuel, L., and Zellner, R.: Deliquescence and efflorescence behavior of ternary inorganic/organic/water aerosol particles, J. Phys. Chem. A, 116, 6199-6210, doi:10.1021/jp211522t, 2012.

Peng, C., Chan, M. N., and Chan, C. K.: The hygroscopic properties of dicarboxylic and multifunctional acids: Measurements and UNIFAC predictions, Environ. Sci. Technol., 35, 4495-4501, doi:10.1021/es0107531, 2001.

Petters, M. D. and Kreidenweis, S. M.: A single parameter representation of hygroscopic growth and cloud condensation nucleus activity, Atmos. Chem. Phys., 7, 1961-1971, doi:10.5194/acp-71961-2007, 2007.

Petters, M. D., Carrico, C. M., Kreidenweis, S. M., Prenni, A. J., DeMott, P. J., Collett Jr., J. L., and Moosmueller, H.: Cloud condensation nucleation activity of biomass burning aerosol, J. Geophys. Res.-Atmos., 114, D22205, doi:10.1029/2009jd012353, 2009.

Pope, F. D., Dennis-Smither, B. J., Griffiths, P. T., Clegg, S. L., and Cox, R. A.: Studies of single aerosol particles containing malonic acid, glutaric acid, and their mixtures with sodium chloride. I. Hygroscopic growth, J. Phys. Chem. A, 114, 5335-5341, doi:10.1021/jp100059k, 2010.

Pöschl, U.: Atmospheric aerosols: Composition, transformation, climate and health effects, Angew. Chem. Int. Ed., 44, 7520 7540, doi:10.1002/anie.200501122, 2005.

Prenni, A. J., DeMott, P. J., Kreidenweis, S. M., Sherman, D. E., Russell, L. M., and Ming, Y.: The effects of low molecular weight dicarboxylic acids on cloud formation, J. Phys. Chem. A, 105, 11240-11248, doi:10.1021/jp012427d, 2001.

Prenni, A. J., De Mott, P. J., and Kreidenweis, S. M.: Water uptake of internally mixed particles containing ammonium sulfate and dicarboxylic acids, Atmos. Environ., 37, 4243-4251, doi:10.1016/s1352-2310(03)00559-4, 2003.

Pruppacher, H. R. and Klett, J. D.: Microphysics of Clouds and Precipitation, 2nd Edn., Springer Publications, New York, USA, 1997.

Ramanathan, V., Crutzen, P. J., Kiehl, J. T., and Rosenfeld, D.: Atmosphere - aerosols, climate, and the hydrological cycle, Science, 294, 2119-2124, doi:10.1126/science.1064034, 2001.

Rickards, A. M., Miles, R. E., Davies, J. F., Marshall, F. H., and Reid, J. P.: Measurements of the sensitivity of aerosol hygroscopicity and the kappa parameter to the $\mathrm{O} / \mathrm{C}$ ratio, J. Phys. Chem. A, 117, 14120-14131, doi:10.1021/jp407991n, 2013.

Saxena, P. and Hildemann, L. M.: Water-soluble organics in atmospheric particles: A critical review of the literature and application of thermodynamics to identify candidate compounds, J. Atmos. Chem., 24, 57-109, doi:10.1007/bf00053823, 1996.

Saxena, P., Hildemann, L. M., McMurry, P. H., and Seinfeld, J. H.: Organics alter hygroscopic behavior of atmospheric particles, J. Geophys. Res.-Atmos., 100, 18755-18770, doi:10.1029/95jd01835, 1995.

Schneidemesser, E. V., Monks, P. S., Allan, J. D., Bruhwiler, L., Forster, P., Fowler, D., Lauer, A., Morgan, W. T., Paasonen, P., Righi, M., Sindelarova, K., and Sutton, M. A.: Chemistry and the linkages between air quality and climate change, Chem. Rev., 115, 3856-3897, doi:10.1021/acs.chemrev.5b00089, 2015.

Simoneit, B. R. T., Schauer, J. J., Nolte, C. G., Oros, D. R., Elias, V. O., Fraser, M. P., Rogge, W. F., and Cass, G. R.: Levoglucosan, a tracer for cellulose in biomass burning and atmospheric 
particles, Atmos. Environ., 33, 173-182, doi:10.1016/s13522310(98)00145-9, 1999.

Stokes, R. H. and Robinson, R. A.: Interactions in aqueous nonelectrolyte solutions .I. Solute-solvent equilibria, J. Phys. Chem., 70, 2126-2131, doi:10.1021/j100879a010, 1966.

Stolzenburg, M. R. and McMurry, P. H.: Equations governing single and tandem DMA configurations and a new lognormal approximation to the transfer function, Aerosol Sci. Tech., 42, 421-432, doi:10.1080/02786820802157823, 2008.

Suda, S. R., Petters, M. D., Yeh, G. K., Strollo, C., Matsunaga, A., Faulhaber, A., Ziemann, P. J., Prenni, A. J., Carrico, C. M., Sullivan, R. C., and Kreidenweis, S. M.: Influence of functional groups on organic aerosol cloud condensation nucleus activity, Environ. Sci. Technol., 48, 10182-10190, doi:10.1021/es502147y, 2014.

Svenningsson, B., Rissler, J., Swietlicki, E., Mircea, M., Bilde, M., Facchini, M. C., Decesari, S., Fuzzi, S., Zhou, J., Mønster, J., and Rosenørn, T.: Hygroscopic growth and critical supersaturations for mixed aerosol particles of inorganic and organic compounds of atmospheric relevance, Atmos. Chem. Phys., 6, 1937-1952, doi:10.5194/acp-6-1937-2006, 2006.

Varga, Z., Kiss, G., and Hansson, H.-C.: Modelling the cloud condensation nucleus activity of organic acids on the basis of surface tension and osmolality measurements, Atmos. Chem. Phys., 7, 4601-4611, doi:10.5194/acp-7-4601-2007, 2007.

Wexler, A. S. and Clegg, S. L.: Atmospheric aerosol models for systems including the ions $\mathrm{H}^{+}, \mathrm{NH}_{4}^{+}, \mathrm{Na}^{+}, \mathrm{SO}_{4}^{2-}, \mathrm{NO}_{3}^{-}$, $\mathrm{Cl}^{-}, \mathrm{Br}^{-}$, and $\mathrm{H}_{2} \mathrm{O}$, J. Geophys. Res.-Atmos., 107, 4207, doi:10.1029/2001jd000451, 2002.

Wise, M. E., Surratt, J. D., Curtis, D. B., Shilling, J. E., and Tolbert, M. A.: Hygroscopic growth of ammonium sulfate/dicarboxylic acids, J. Geophys. Res.-Atmos., 108, 4638, doi:10.1029/2003jd003775, 2003.

Wittig, R., Lohmann, J., and Gmehling, J.: Vapor-liquid equilibria by UNIFAC group contribution. 6. Revision and extension, Ind. Eng. Chem. Res., 42, 183-188, doi:10.1021/ie0205061, 2003.

Xu, W., Guo, S., Gomez-Hernandez, M., Zamora, M. L., Secrest, J., Marrero-Ortiz, W., Zhang, A. L., Collins, D. R., and Zhang, R.: Cloud forming potential of oligomers relevant to secondary organic aerosols, Geophys. Res. Lett., 41, 6538-6545, doi:10.1002/2014GL061040, 2014.
Yeung, M. C. and Chan, C. K.: Water content and phase transitions in particles of inorganic and organic species and their mixtures using micro-Raman spectroscopy, Aerosol Sci. Tech., 44, 269280, doi:10.1080/02786820903583786, 2010.

Zamora, I. R. and Jacobson, M. Z.: Measuring and modeling the hygroscopic growth of two humic substances in mixed aerosol particles of atmospheric relevance, Atmos. Chem. Phys., 13, 89738989, doi:10.5194/acp-13-8973-2013, 2013.

Zamora, I. R., Tabazadeh, A., Golden, D. M., and Jacobson, M. Z.: Hygroscopic growth of common organic aerosol solutes, including humic substances, as derived from water activity measurements, J. Geophys. Res.-Atmos., 116, D23207, doi:10.1029/2011jd016067, 2011.

Zardini, A. A., Sjogren, S., Marcolli, C., Krieger, U. K., Gysel, M., Weingartner, E., Baltensperger, U., and Peter, T.: A combined particle trap/HTDMA hygroscopicity study of mixed inorganic/organic aerosol particles, Atmos. Chem. Phys., 8, 55895601, doi:10.5194/acp-8-5589-2008, 2008.

Zhang, Q., Jimenez, J. L., Canagaratna, M. R., Allan, J. D., Coe, H., Ulbrich, I., Alfarra, M. R., Takami, A., Middlebrook, A. M., Sun, Y. L., Dzepina, K., Dunlea, E., Docherty, K., DeCarlo, P. F., Salcedo, D., Onasch, T., Jayne, J. T., Miyoshi, T., Shimono, A., Hatakeyama, S., Takegawa, N., Kondo, Y., Schneider, J., Drewnick, F., Borrmann, S., Weimer, S., Demerjian, K., Williams, P., Bower, K., Bahreini, R., Cottrell, L., Griffin, R. J., Rautiainen, J., Sun, J. Y., Zhang, Y. M., and Worsnop, D. R.: Ubiquity and dominance of oxygenated species in organic aerosols in anthropogenically-influenced Northern Hemisphere midlatitudes, Geophys. Res. Lett., 34, L13801, doi:10.1029/2007g1029979, 2007.

Zhang, Q. N., Zhang, Y., Cai, C., Guo, Y. C., Reid, J. P., and Zhang, Y. H.: In situ observation on the dynamic process of evaporation and crystallization of sodium nitrate droplets on a $\mathrm{ZnSe}$ substrate by FTIR-ATR, J. Phys. Chem. A, 118, 2728-2737, doi:10.1021/jp412073c, 2014. 